\title{
Genome-wide transcript and protein analysis reveals distinct features of aging in the mouse heart
}

Isabela Gerdes Gyuricza ${ }^{1}$, Joel M. Chick ${ }^{2}$, Gregory R. Keele ${ }^{1}$, Andrew G. Deighan ${ }^{1}$, Steven C. Munger ${ }^{1}$, Ron Korstanje ${ }^{1}$, Steven P. Gygi ${ }^{3}$, Gary A. Churchill ${ }^{1}$

${ }^{1}$ The Jackson Laboratory, Bar Harbor, Maine 04609 USA;

${ }^{2}$ Vividion Therapeutics, San Diego, California 92121, USA;

${ }^{3}$ Harvard Medical School, Boston, Massachusetts 02115, USA

Corresponding author: gary.churchill@jax.org

Key words for online indexing:

Heart

Aging

Transcriptomics

Proteomics

eQTL

PQTL

Stoichiometry

\section{ABSTRACT}

Investigation of the molecular mechanisms of aging in the human heart is challenging due to confounding factors, such as diet and medications, as well limited access to tissues. The laboratory mouse provides an ideal model to study aging in healthy individuals in a controlled environment. However, previous mouse studies have examined only a narrow range of the genetic variation that shapes individual differences during aging. Here, we analyzed transcriptome and proteome data from hearts of genetically diverse mice at ages 6,12 and 18 months to characterize molecular changes that occur in the aging heart. Transcripts and proteins reveal distinct biological processes that are altered through the course of natural aging. Transcriptome analysis reveals a scenario of cardiac hypertrophy, fibrosis, and reemergence of fetal gene expression patterns. Proteome analysis reveals changes in energy metabolism and protein homeostasis. We found that for many protein complexes there is a decline in correlation between their component proteins with age, indicating age-related loss of stoichiometry. Some of the most affected complexes are themselves involved in protein homeostasis, which potentially contributes to a viscious cycle of progressive breakdown in protein quality control with age. In addition, we identified genetic loci that modulate age-related changes in a variety of cellular processes, including protein degradation and sorting, suggesting that genetic variation can alter the rate of molecular aging. 


\section{INTRODUCTION}

Cardiovascular (CV) diseases are the leading cause of death in elderly people. Improved understanding of mechanisms that underlie the changes that occur in the aging heart could open new opportunities for prevention and treatment (1). As the heart ages, characteristic physiological changes occur, including increased arterial thickening and stiffness, endothelium dysfunction, valvular fibrosis and calcification, and a switch from fatty acid to glucose metabolism (2-4). Compensatory mechanisms may temporarily maintain heart function but can also contribute to progressive deterioration and eventual heart failure (2). For example, thickening of the left ventricle and remodeling of the extracellular matrix may compensate for loss of systolic function $(2,3)$. However, in the long term, the increased wall stress causes the left ventricle to dilate, leading to a decline in systolic function (5). Physiological measures of cardiac function that change with age have high heritability suggesting that genetic factors contribute to variability in cardiac aging in humans (6).

Despite well-known physiological changes in the aging heart, dissecting the cellular and molecular basis of age-related change is challenging due to its complex dynamics and inherent variability in the aging process $(7,8)$. Age-related changes at the cellular levels have been associated with genomic instability, loss of protein homeostasis, epigenetic alterations, mitochondrial dysfunction and inflammation (7). Variability of transcript expression increases with age in mammalian tissues, including the heart $(9,10)$. Age-related dysregulation of transcripts is offset by selective translation, and post-transcriptional mechanisms become crucial for achieving cellular homeostasis (11). The investigation of molecular mechanisms involved in aging is further complicated by the uncoupling of age-related changes between transcripts and their corresponding proteins (12). Waldera-Lupa et al (2014) found that $77 \%$ of the proteins that change with age in human fibroblasts showed no corresponding change in their transcripts (13). Decoupling between transcripts and proteins with age has also been observed in the brain of humans and rhesus macaques (14). Thus, investigating age-related changes using only transcriptional profiling may fail to reveal important influences on proteins and higher-order cellular processes.

Mouse models of aging can recapitulate many of the cardiac aging phenotypes seen in humans, such as increased atrial and ventricular dimensions and reduced diastolic function (15), and thus provide relevant models for investigating aging processes in the heart. However, most previous studies have used mice descended from only a few isogenic strains that do not reflect the diversity of cardiac phenotypes found in aging human populations. Multiple studies report differences in mouse cardiac phenotypes, 
under either physiological or pathological conditions, associated with genetic background across inbred strains (16-20), and in multiparent populations $(21,22)$, confirming the importance of genetic diversity in shaping the rate and course of cardiac aging.

In this study we utilize Diversity Outbred (DO) mice derived from eight inbred founder strains: A/J (AJ), C57BL/6J (B6), 129S1Sv/ImJ (129), NOD/ShiltJ (NOD), NZO/H1LtJ (NZO), CAST/EiJ (CAST), PWK/PhJ (PWK), and WSB/EiJ (WSB), to investigate cardiac aging in a genetic and phenotypically diverse model $(23,24)$. We analyze transcriptome data from RNA sequencing (RNA-seq) and protein data from mass-spectrometry analysis of heart tissues collected from healthy DO mice at ages 6, 12 and 18 months. At 6 months of age, the mice have reached full maturity. At 18 months, most mice are healthy and are only beginning to show signs of age-related decline. Thus, we are looking at changes in transcripts and proteins that are not influenced by developmental programs and are also not reflecting late-stage disease progression (25). These data can reveal broad patterns of change in biological processes and in specific cellular compartments. To characterize molecular and cellular changes in the aging mouse heart, we first identify the transcripts and proteins that are changing with age and identify functionally related groups of genes using gene-set enrichment analysis $(26,27)$. We then examine the maintenance of protein complex stoichiometry. Finally, we investigate how genetic variation modulates age-related changes in the heart. The molecular profiling data from the mouse heart are freely available to support further investigations of the molecular basis of aging in mammals (https://qtlviewer.jax.org/viewer/agingheart). 


\section{RESULTS}

Transcriptomics reveals age-related changes in muscle cell differentiation, contraction, and inflammation

We used RNA-Seq data from the hearts of 192 DO mice of both sexes aged to 6, 12 or 18 months to identify transcripts that change with age (Figure 1). Transcripts that change with age are referred to throughout as age-related transcripts, and their magnitude and direction of change are referred to as age effects, reported in unit of $\log _{2}$ fold change per year. For the transcriptome data, we used DESeq2 (28) to identify 2,287 transcripts (out of 20,932) with significant age-related changes (false discovery rate, FDR < 0.1; Supplementary File 1). These transcripts include genes that are known to play a role in the aging heart, as well as genes that have been implicated in aging but have not been previously reported as changing in the heart, or genes that play a role in heart disease or heart development but have not been reported to change with age. They are enriched for functional annotations across 85 biological processes (FDR $<0.05)$, the most significant of which are muscle cell migration, regulation of muscle cell differentiation, ion transport pathways, and acute-phase response (Figure 2).

Some of the age-related transcripts possess functions relevant to cardiac pathological conditions and heart development (Table 1). Both Adamts1, present in the muscle cell migration pathway, and Serpine1, present in both muscle cell migration and ion transport pathways, increase with age (Adamts1: age effect $=0.15$; Serpine1: age effect $=0.19 ;$ Figure 3A). These genes have been shown to induce collagen 1 deposition and fibrosis in the heart (29-31). The increased expression of transcripts involved in fibrosis is indicative of age-related changes in cellular composition including an increase in the proportion of fibroblasts and myofibroblasts in the heart. Comparing the age-related transcripts reported here with published single-cell RNA-seq data (18), we observe an increase in expression of fibroblast markers including Timp1 (age effect $=0.3$ ) and Mt2 (age effect $=0.4$ ), and an increase in myofibroblast markers including Postn (age effect $=0.3$ ) and Cthrc1 (age effect $=0.46$ ). We also observed increased expression of Nov (age effect $=0.18$; Figure $3 \mathrm{~A}$ ), which plays a role in heart development by blocking terminal differentiation and increasing the proliferation rate of myoblasts $(34,35)$.

The gene Myocd, whose expression decreases with age (age effect $=-0.12$; Figure 3B), is involved in both muscle cell migration and muscle cell differentiation, and it is an important regulator of cardiac function by maintaining cardiomyocyte cell structure and function (34). Ppara also decreases with age (age effect $=-0.11-$ Figure $3 \mathrm{~B}$ ), and it plays a role in the regulation of cardiac fatty acid metabolism and is 
implicated in several pathologic heart conditions associated with aging $(35,36)$. Many age-related transcripts that are associated with calcium ion transport, including PIn, Cacna1g and Dhrs7c, decrease with age (Table 1 and Figure 3B). These genes have functions associated with cardiac muscle contraction, play a role in cardiomyopathy, and are downregulated in heart failure models but have not been previously described in the aging heart (37-39).

Acute phase response pathway genes, which are involved in inflammation, increase with age except for Stat5b, which decreases (age effect $=-0.07$; Figure 3B). Although its function in heart is not established, STAT5B interacts with the insulin receptor, coordinating changes in gene expression through insulin signaling $(40,41)$. In addition, STAT5B was proposed to inhibit acute-phase response by modulating the activation of STAT3 (42). Transcripts in the acute phase response pathway that increase with age include Ahsg (age effect = 0.3; Figure $3 \mathrm{~A}$ ), which controls the binding of free fatty-acid to inflammatory receptors and protects against vascular calcification $(43,44)$, and Tnfsf11 (age effect $=0.52-$ Figure 3A), which is involved in aortic valve calcification in response to inflammation, a feature prevalent in the elderly (45). We observe an age-related increase in expression of immune cell-specific markers, such as B cells $(C d 79 a$, age effect $=0.46)$, macrophages $(C d 68$, age effect $=0.19)$ and monocytes (Plac8, age effect $=0.6)$, indicating immune cell infiltration in the aging heart. The increase in expression of immune response genes with age in multiple tissues of the mouse, including heart, has been reported previously (46). 


\section{Study design}

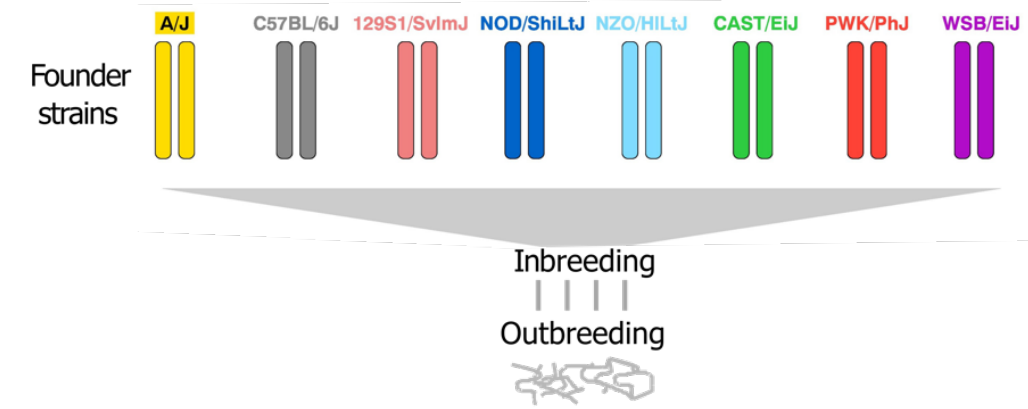

Diversity outbred (DO) mice

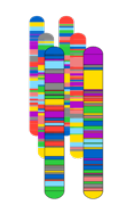

6 months

$(\mathrm{N}=64)$

Bulk heart
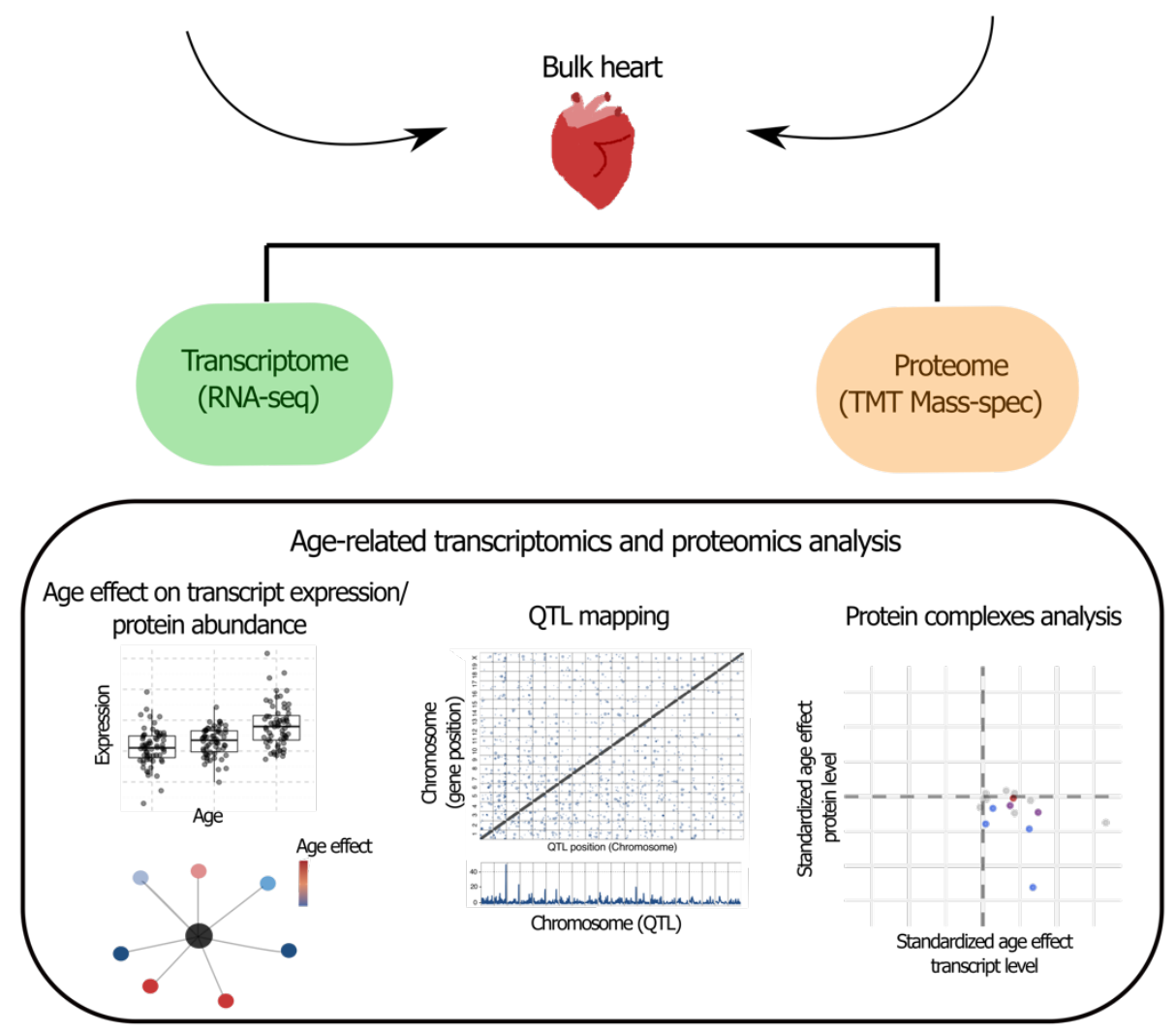

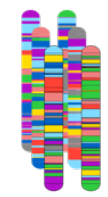

18 months

$(\mathrm{N}=64)$

Figure 1. Study Design. We carried out a cross-sectional aging study of DO mice, which are descendant from 8 founder inbred strains and are maintained as an outbred stock with high levels of heterozygosity. Heart tissue from DO mice aged 6, 12 or 18 months was collected for RNA-seq and mass-spectrometry analysis. The transcriptome and proteome data were analyzed to evaluate age-related changes in transcript and protein abundance using gene set enrichment, QTL mapping and protein complex stoichiometry. 


\section{Enriched gene ontology terms for age-related transcripts}

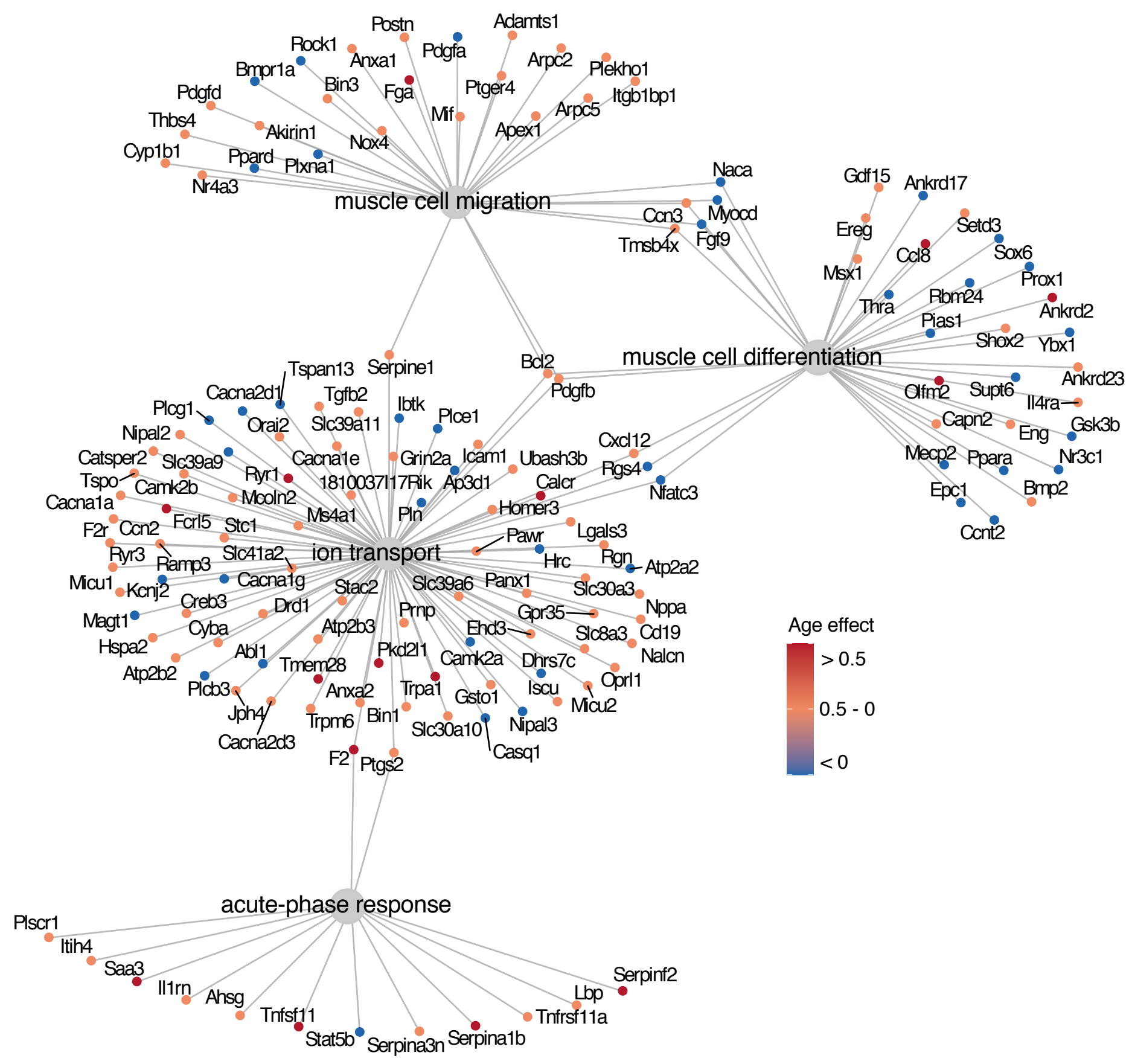

Figure 2. Enriched gene ontology terms for age-related transcripts. The most significant gene ontology categories for age-related transcripts in DO mouse hearts are shown. Gene-set enrichment analysis reveals that age-related transcripts are involved in muscle cell migration, regulation of muscle cell differentiation, ion transport and acutephase response (FDR $<0.05$ ). Major nodes indicate enriched categories and adjacent nodes identify transcripts within each category. Transcripts involved in muscle cell migration, muscle cell differentiation and ion transport both increase and decrease with age. Transcripts from the acute-phase response increase except for Stat5b. The color scale represents the age effect for each transcript in units of $\log _{2}$ fold change (LFC) per year. 
Individual-level expression of age-related transcripts

A

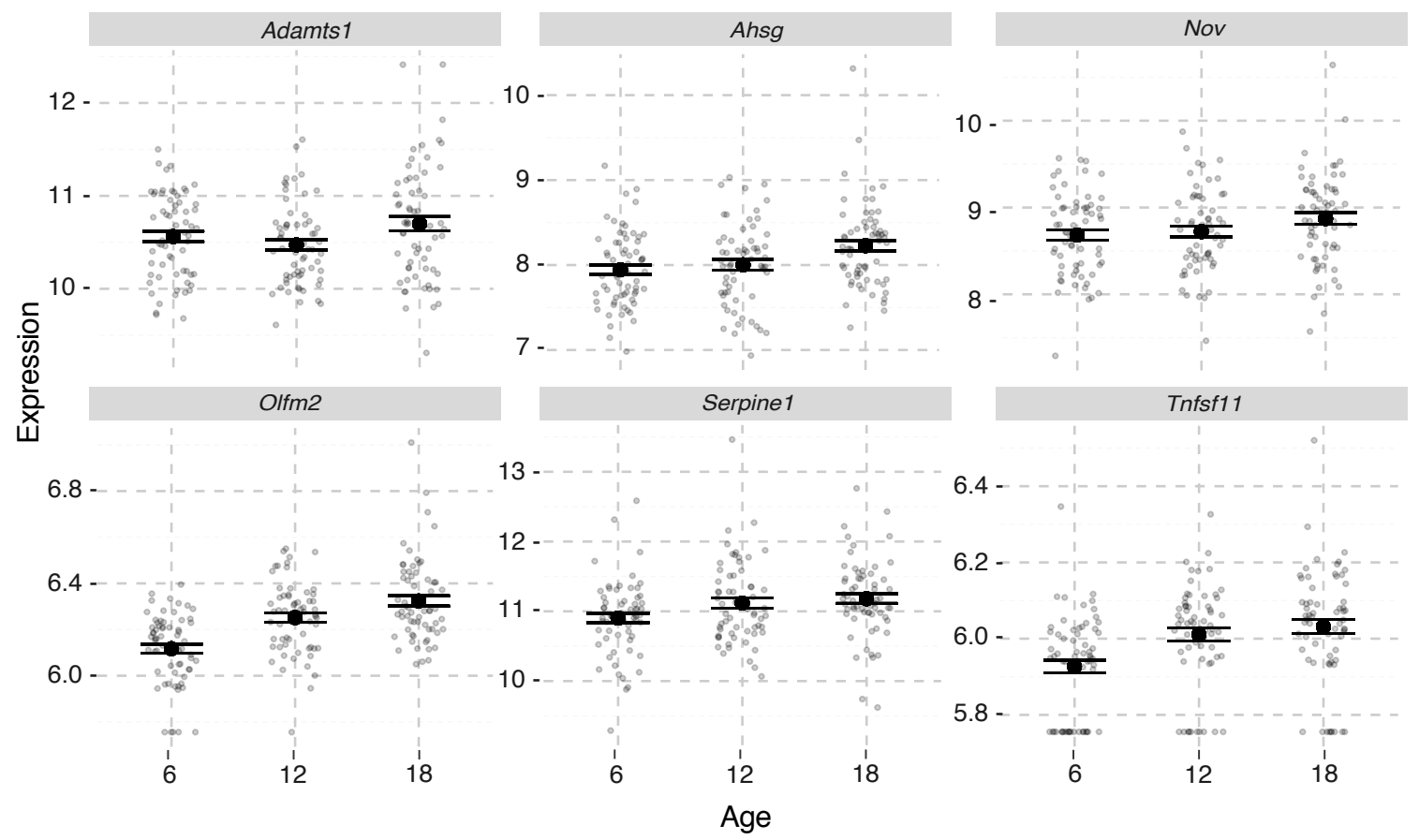

B

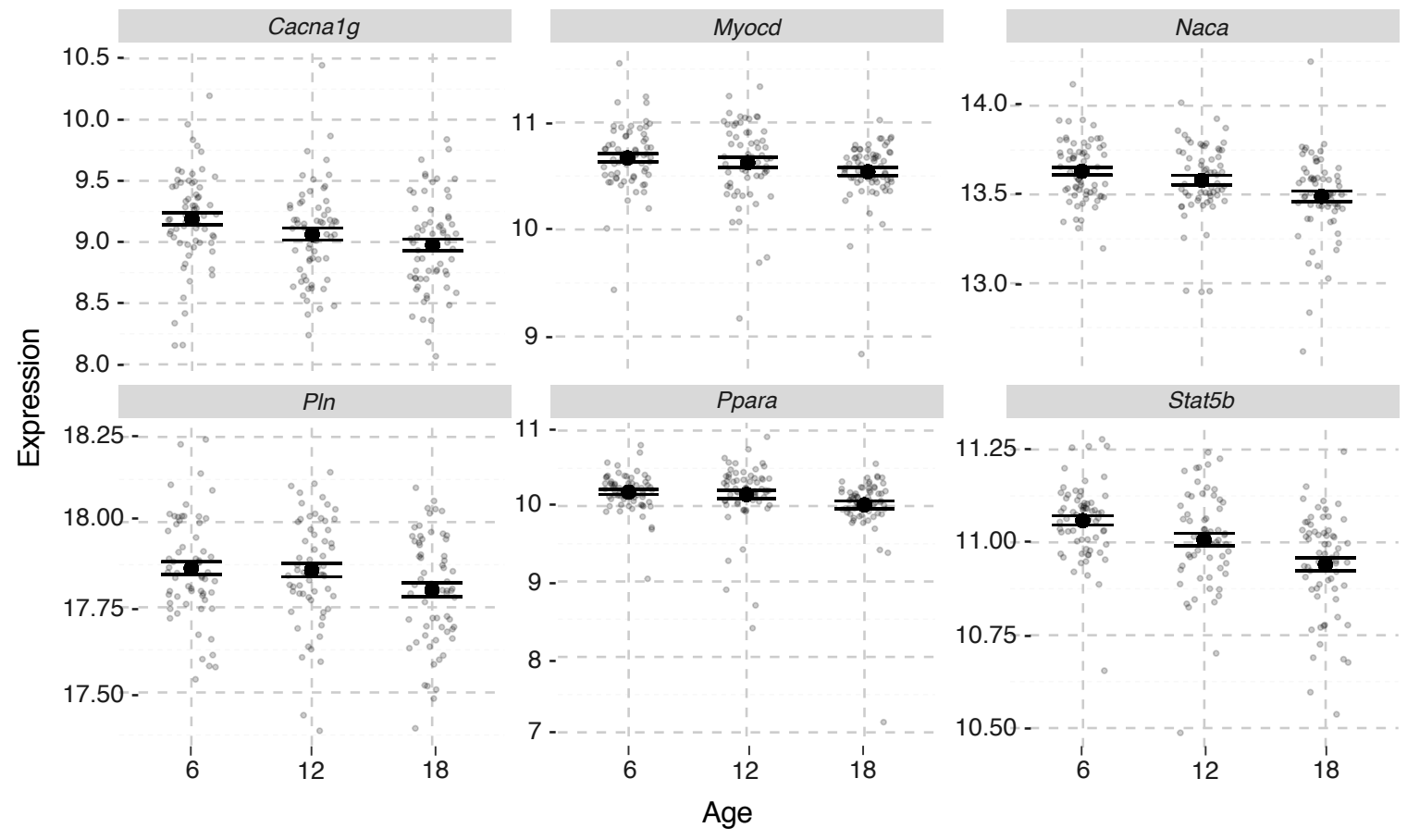

Figure 3. Individual-level expression of age-related transcripts. Transcripts highlighted in Table 1 are shown across age groups (6, 12 and 18 months). Transcripts increase (A) or decrease (B) with age. Solid points represent the age group mean expression +/- 1 standard error (SE), and points with transparency show individual mouse expression levels. Expression levels ( $Y$ axis) are counts normalized by the DESeq2 variance stabilizing transformation. 


\section{Proteomics reveals age-related changes in mitochondrial metabolism and intracellular protein transport}

We obtained proteomics data from 190 of the 192 DO mice that had transcriptome data (Figure 1). In order to test for age-related changes at the protein level, we fit a regression model of protein abundances with a linear term for age and covariates as described in Methods. We identified 1,161 agerelated proteins (out of 4,062; FDR < 0.05; Supplementary File 2). A higher proportion of proteins exhibited change with age when compared to transcripts, and thus we applied a more stringent FDR threshold to focus on the proteins with greatest change. These proteins are enriched (FDR $<0.05)$ for gene ontology categories that include positive regulation of cellular proliferation, intracellular protein transport and several mitochondrial categories (Figure 4; Table 2). Changes in the mitochondrial respiratory chain complexes were also reported in recent studies of single-cell RNA-seq and proteome data of multiple tissues in aging mice $(46,47)$. Interestingly, there was no overlap of enrichment terms for proteins and those found in our transcriptome analysis. The proteome data also highlight different cell-specific markers (18). In addition to fibroblast markers, we see an increase with age in markers of smooth muscle (VTN, age effect $=0.58$ ), epicardium (CLU, age effect $=0.38)$ and endothelium cells (FABP4, age effect $=0.39$ and PECAM1, age effect $=0.3$ ) that were not seen in the transcriptome data. Thus, the protein data reveal unique features aging that are not seen at the transcript level.

The serine/threonine kinases AKT1 and AKT2 are highly abundant in cardiomyocytes and regulate cellular proliferation and intracellular protein transport pathways. Both are significantly increasing in abundance with age (AKT1: age effect $=0.36$; AKT2: age effect $=0.27-$ Figure 5A). AKT1 and AKT2 respond differently to growth factors and extracellular ligands (48), but they both participate in the regulation of cardiac hypertrophy in aging through interaction with Sirtuins (49). Knockout mouse models have shown that the lack of AKT1 constrains the ability of cardiomyocytes to respond to physiological hypertrophy. Alternatively, AKT2 mutant mice showed reduced glucose oxidation in heart cells, but normal response to exercise-induce hypertrophy, demonstrating that these two proteins regulate heart remodeling in response to stress in distinct ways $(48,50,51)$. Along with AKT2, other proteins associated with fetal metabolism increase with age, including ACACB (age effect $=0.14$ ), which inhibits fatty acid oxidation, and GYS1 (age effect $=0.23$ ), which plays a role in glucose metabolism $(50,52,53)$.

RAB family proteins are Ras-like GTPases that regulate protein trafficking by vesicle formation and fusion throughout the cell $(54,55)$. Among the 22 RAB proteins that change with age, 19 are increasing 
(Supplementary File 2). Some RAB proteins are activated during mitophagy, which is mediated by RABGEF1 in mammalian cultured cells (56). Notably, RABGEF1 is the RAB family member with the greatest age-related increase (age effect $=0.74$; Figure $5 \mathrm{~A}$ ), suggesting that mitophagy may play a substantial role in the aging heart. Increased myocardial RAB abundance is associated with myocardial hypertrophy. Mice overexpressing RAB1A showed contractile depression with impaired calcium reuptake and developed hypertrophy that progressed to heart failure (54). RAB1A and RAB1B are mostly identical in structure and function (57) and RAB1B is one of the few RAB proteins that decreased with age in our dataset (age effect $=-0.356$; Figure 5B).

We observed distinct patterns of age-related changes in proteins of the mitochondrial respiratory complexes (Figure 5 - Figure supplement 1). Among 16 proteins in the cytochrome C oxidase (COX) complex, i.e., mitochondrial respiratory chain complex IV, 7 show significant age-related changes and, of those, 6 increase in abundance with age. The exception is ACTN3 (alpha-actinin-3), which was decreasing with age (age effect = -1.8; Figure 5B). A role for ACTN3 has not been described in the heart, but in skeletal muscle, it is known to be a negative regulator of oxidative metabolism. Depletion of ACTN3 results in overexpression of COX proteins and to higher mitochondrial oxidative metabolism $(58,59)$. Our findings suggest that there is an increase in oxidative mitochondrial metabolism in the aging heart (Figure 5A; Figure 5 - Figure supplement 1). Most proteins from the SDH and ATP families (succinate dehydrogenase complex - Complex II and ATP synthase complex - Complex V, respectively) increase with age (Figure 5A; Figure 5 - Figure supplement 1 ). In contrast, subunits from the mitochondrial complex I, i.e. NDUF family (NADH: ubiquinone oxidoreductase supernumerary subunits - Complex I), change in both directions with age (Figure 5A; Figure 5B; Figure 5 - Figure supplement 1 ). 
bioRxiv preprint doi: https://doi.org/10.1101/2020.08.28.272260; this version posted April 21, 2021. The copyright holder for this preprint (which

was not certified by peer review) is the author/funder, who has granted bioRxiv a license to display the preprint in perpetuity. It is made available under aCC-BY-NC-ND 4.0 International license.

\section{Enriched gene ontology terms for age-related proteins}

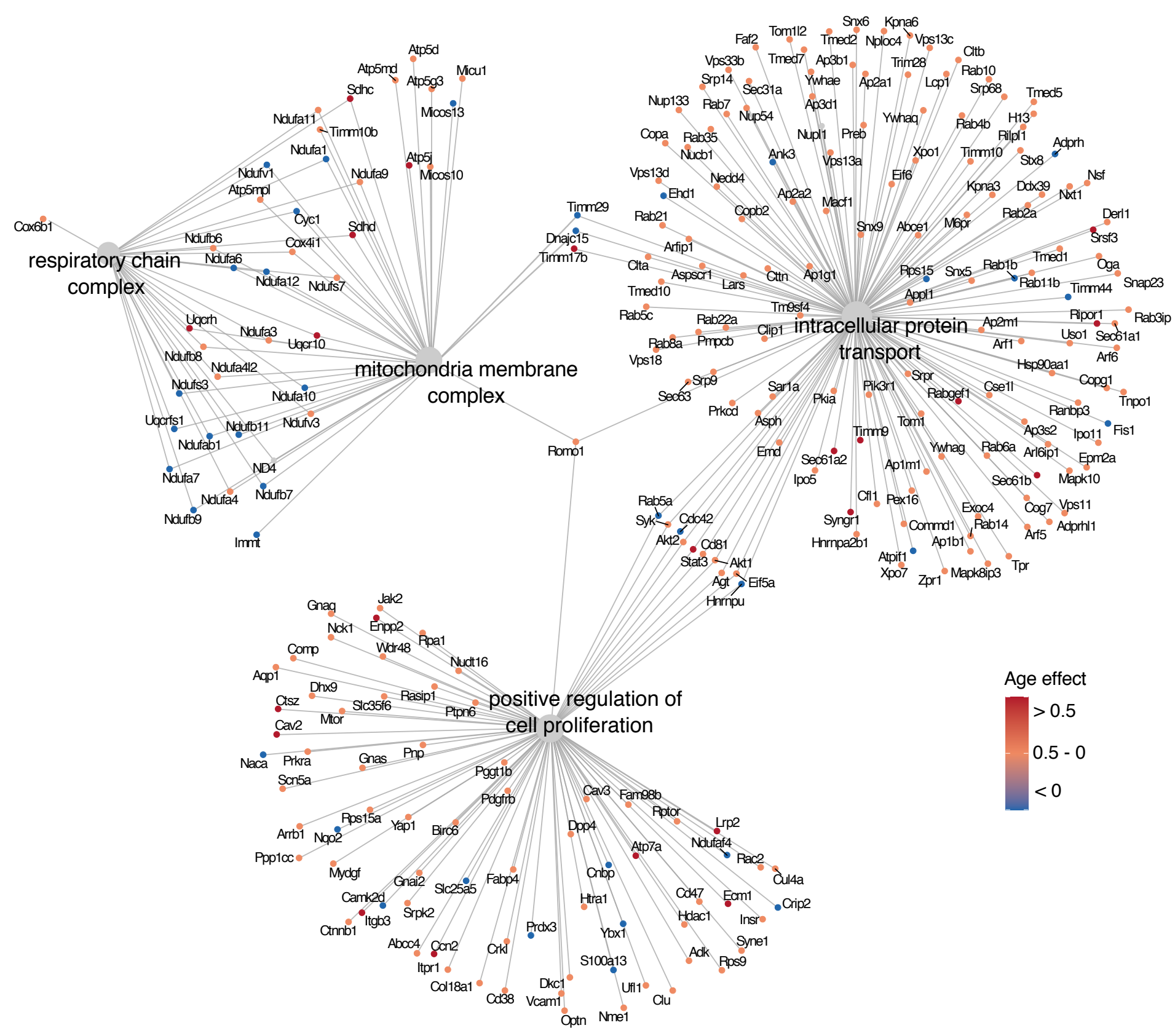

Figure 4. Enriched gene ontology terms for age-related proteins. The most significant gene ontology categories for age-related proteins in DO mouse hearts. Gene-set enrichment analysis reveals that proteins changing with age are involved in positive regulation of cell proliferation, intracellular protein transport, mitochondria membrane complex and respiratory chain complex (FDR $<0.05)$. Major nodes indicate enriched gene ontology terms and adjacent nodes identify age-related proteins within each category. Most age-related proteins increase in abundance with age, including proteins involved in intracellular protein transport and positive regulation of cell proliferation. Color scale represents the age effect in units of LFC per year. 


\section{Individual-level expression of age-related proteins}

A

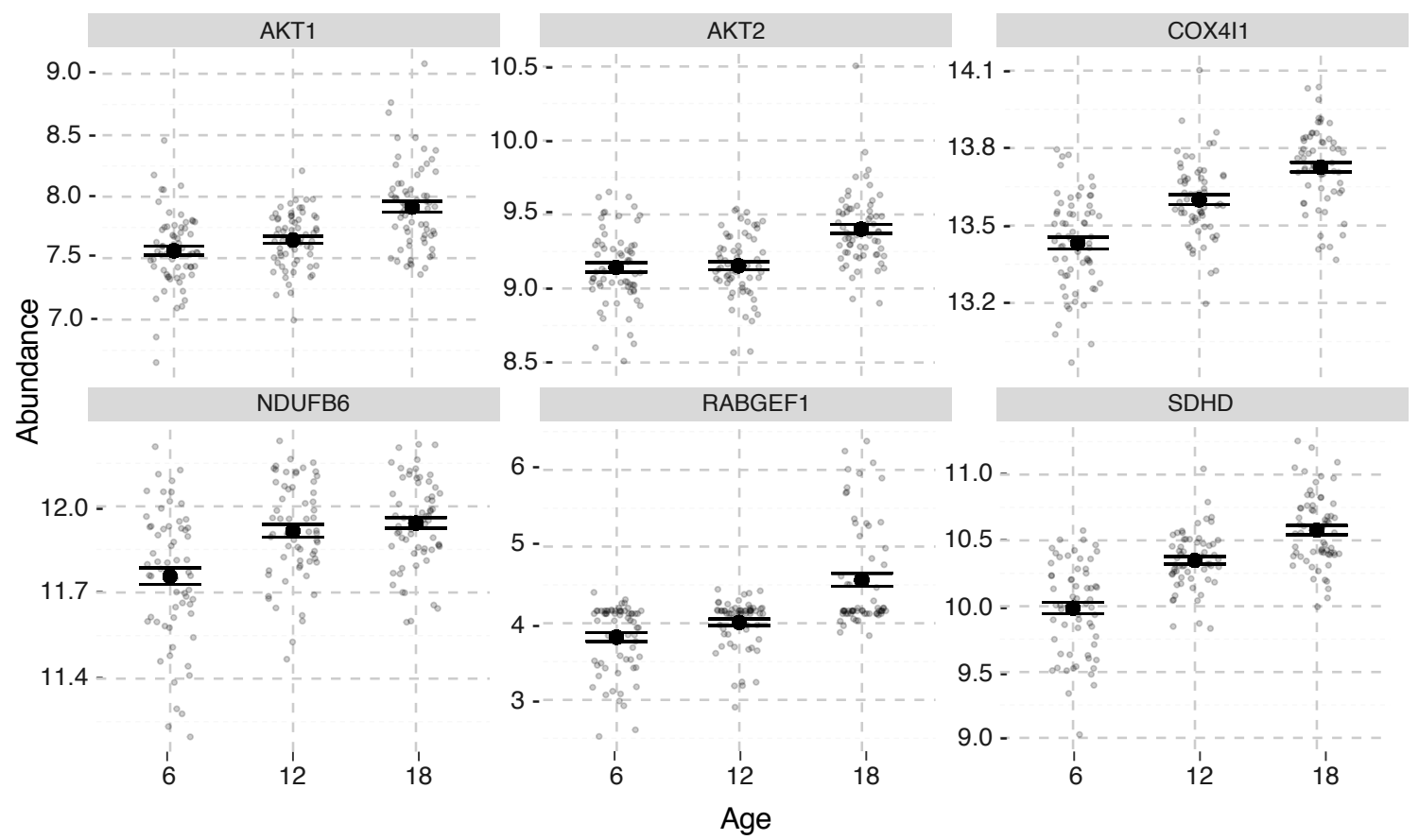

B
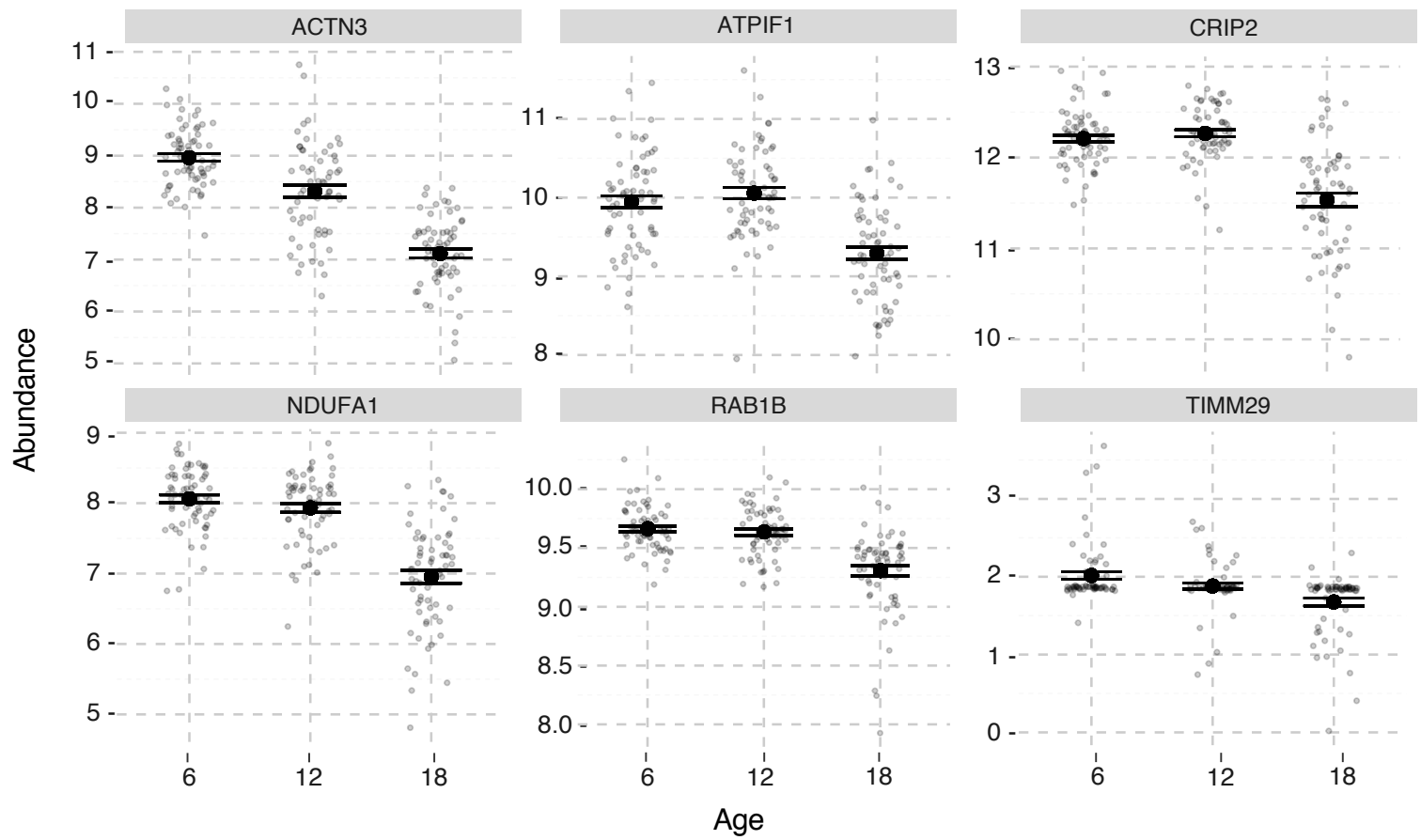

Figure 5. Individual-level expression of age-related proteins. Abundance of proteins highlighted in Table 2 across age groups (6, 12 and 18 months) shows proteins that increase (A) or decrease (B) with age. Solid points represent the age group mean expression $+/-1$ standard error (SE), and points with transparency show individual mouse abundance. Abundances ( $\mathrm{Y}$ axis) are normalized $\log _{2}$ values from mass-spec quantification (Methods). 


\section{Dysregulation of protein complex stoichiometry with age}

Loss of stoichiometry in protein complexes has been shown to occur with age in a number of organisms (60-63). We examined the balance of gene-pairs, for both transcript expression and protein abundance, in the mouse heart for 16 complexes as defined in the CORUM database (64). We selected complexes with transcripts and proteins present in our data, including 265 proteasome, nuclear pore complex, cytoplasmic ribosomal small subunit, cytoplasmic ribosomal large subunit, mitochondrial ribosomal large subunit, coat protein I (COPI) vesicle transport, coat protein II (COPII) vesicle transport, mitochondrial ribosomal small subunit, mitochondrial respiratory chain complexes (I-V), mitochondrial pyruvate dehydrogenase complex, mitochondrial inner membrane presequence translocase complex, and mitochondrial outer membrane translocase complex. We computed the Pearson correlations between all pairs of proteins and among all pairs of transcripts within each complex and estimated the age-related changes in correlation (Methods). We evaluated the significance of these changes using a permutation procedure (65).

We identified 123 protein-pairs (out of 2074) with significant changes in correlation with age (FDR <0.1) (Supplementary File 3). Of these, 4 are in the cytoplasmic ribosomal small subunit complex, 11 are in the COPII complex, 27 are from the mitochondrial respiratory chain complexes (5 from mitochondrial complex I, 2 from mitochondrial complex II, 5 from mitochondrial complex III, 4 from mitochondrial complex IV and 11 from the mitochondrial complex V), and 81 are in the $26 \mathrm{~S}$ proteasome complex. The majority (115 out of 123 pairs) of the protein-pair correlations decrease with age, consistent with the expected loss of stoichiometric balance in these complexes.

As mentioned above, changes associated with the $26 \mathrm{~S}$ proteasome complex were outstanding, specially at the protein level. For individual protein pairs, the age effects (change in correlation per year) for all the gene-pairs, including the non-significant ones, range from 0.37 to -0.73 , while for their transcripts, the range is 0.56 to -0.5 (not significant; Figure 6A-D). The $26 \mathrm{~S}$ proteasome complex is composed of two subcomplexes, a core particle (20S proteasome) and a regulatory particle (19S proteasome). The core particle of the proteasome is made up of $\alpha$ and $\beta$ subunits (proteins from the PSMA or PSMB families), while the regulatory particle includes proteins from the PSMC and PSMD families (66). Even though both subcomplexes show significant changes in correlation with age, PSMD14, from the regulatory particle, was found in the greatest number of protein-pairs that change in correlation with age (14), followed by proteins PSMD13 (10) and PSMD11 (9). This suggests that the age-related changes mostly affect the regulatory particle of the proteasome (Figure 6D2). 
Among transcripts, only 20 pairs (out of 2042) showed significant correlation change with age $(F D R<0.1)$. All of these are in mitochondrial complexes (3 from mitochondrial complex III, 15 from mitochondrial complex $\mathrm{V}$, and 2 pairs from the mitochondrial pyruvate dehydrogenase complex). Interestingly, all of these transcript-pairs increase in correlation with age (Supplementary File 3). Only two of these pairs also showed a significant change at the protein level (Atp5b - Atp5a1 Mitochondrial complex V: protein age effect $=-0.40$; transcript age effect $=0.21$, and Uqcrc2 - Uqcrh Mitochondrial complex III: protein age effect $=0.38$; transcript age effect $=0.30$ ).

As an alternative approach to assess coordinated changes across an entire protein complex, we fit a joint model to each set of within-complex correlations with a random intercept term for each genepair and a common slope to capture the average correlation change for the complex (Methods). We applied the same permutation test to evaluate statistical significance, but because there is one test per complex, we applied a nominal significance threshold $(p<0.05)$ per complex. Mitochondrial complex III showed an overall change in correlation at the transcript level (age effect $=0.3$ ). We observed changes in only protein correlations for the mitochondrial outer membrane translocase (age effect $=-0.21$ ), nuclear pore complex (age effect $=-0.16$ ), cytoplasmic ribosomal large subunit (age effect $=-0.1$ ) and $26 \mathrm{~S}$ proteasome (protein age effect $=-0.2$ ) (Figure 6E). Mitochondrial complexes IV and $V$ showed change in correlation for both transcripts and proteins (transcript age effect $\sim 0.2$; protein age effect $\sim-0.15$ ). We plotted the age effects at the transcript and protein levels for all 16 complexes (Figure 6E), and note that most complexes, regardless of statistical significance, show an increase in transcript correlations and a decrease in protein correlations. Our findings are consistent with previous reports of protein complex stoichiometry changes reported in killifish brain (62), where protein complexes showing the greatest change with age include the mitochondrial complexes IV and V, the cytoplasmic ribosome, and the 26S proteasome complex. 
bioRxiv preprint doi: https://doi.org/10.1101/2020.08.28.272260; this version posted April 21, 2021. The copyright holder for this preprint (which was not certified by peer review) is the author/funder, who has granted bioRxiv a license to display the preprint in perpetuity. It is made available under aCC-BY-NC-ND 4.0 International license.

\section{Correlation between protein complex members changes with age}
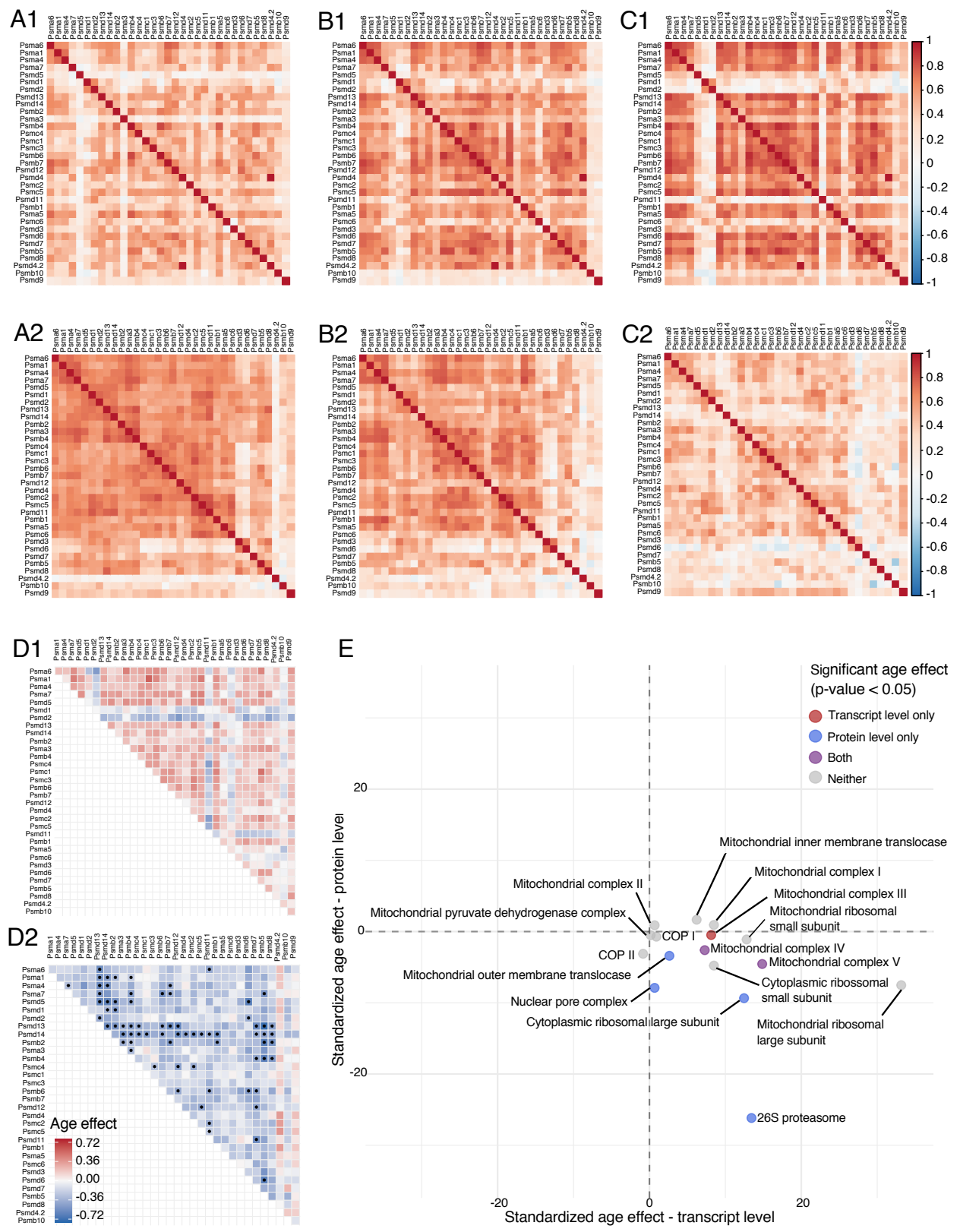

Figure 6. Correlation between protein complex members changes with age. Heatmaps show the correlation coefficients between gene-pairs in the 26S proteasome complex at 6 months (A), 12 months (B) and 18 months (C) at the transcript level (1) and at the protein level (2). D) Heatmaps show the change in correlations between members of the $26 \mathrm{~S}$ proteasome complex. Correlations among transcripts are generally increasing with age but the change is not statistically significant (D1). The majority of correlations among proteins (D2) are decreasing with age. Dots on the heatmap indicate significant changes in correlations with age (FDR $<0.1)$. E) Standardized age effects on correlation for 16 protein complexes are shown for transcripts ( $x$-axis) and proteins ( $y$-axis). Color indicates the significance of the age effect on transcripts, proteins, both or neither. Even though many of the complexes do not show a significant change with age, the direction of changes tends to be increasing for transcripts and decreasing for proteins. Age effects are estimated by linear regression and reported as change in the correlation coefficient per year. 


\section{Genetic variants alter the age trajectory of functionally related groups of proteins}

We carried out genetic mapping analysis of transcripts and proteins to identify quantitative trait loci (eQTL and pQTL, respectively) that regulate their expression/abundance levels. The additive effects of genetic variation on transcripts and proteins have been widely documented (67-71) and will not be discussed here. Our interest is to investigate how genetic variants influence the rate or direction of change with age of transcripts and proteins. To identify these age-interactive QTL (age-QTL), we evaluate an ageby-genotype interaction term in a linear mixed model of genetic effects (Methods) for each transcript and protein. We computed genome-wide adjusted significance using permutation analysis (Methods) and declare age-QTL when the age-interactive $L O D$ score $\left(\operatorname{LOD}_{\text {int }}\right)>7.75$. We have provided access to the data and webtool (QTLviewer) that can be used to explore both the additive and age-interactive genetic effects on transcripts and proteins in the aging mouse heart (https://qtlviewer.jax.org/agingheart). A users' guide for the QTLviewer can also be found at this website (https://qtlviewer.jax.org/userguide).

We found 824 transcript age-QTLs (age-eQTL; Figure 7A; Supplementary File 4). Most age-eQTL mapped to locations that are distant from their coding genes, which suggests that genetic modification of age-related changes is largely not due to direct regulation of gene expression but rather occur in response to other age-related changes. There are, however, five local age-eQTL. A local age-eQTL for the gene Cluh $\left(\operatorname{LOD}_{\text {int }}=7.9\right)$ is located on chromosome 12. This gene binds RNAs of nuclear-encoded mitochondrial proteins, regulating mitochondrial metabolism by translation control and mRNA decay $(72,73)$. Cluh orchestrates mitochondrial metabolic switching from glycolysis to oxidative phosphorylation that happens after birth (73). Genetic variation in Cluh might influence the return to the fetal metabolism in the aging heart.

We found 463 protein age-QTLs (age-pQTL; Figure 7B; Supplementary File 4), all of which are distant from the coding gene. The protein PARK7, which mapped to a distal age-pQTL on chromosome 9 $\left(\operatorname{LOD}_{\text {int }}=10.5\right)$ at $\sim 95 \mathrm{Mb}$, is a redox-sensitive chaperon that protects the murine heart from oxidative damage (74). SIRT2, another protein with relevant function to the aging heart, has a distal age-pQTL on chromosome 13 at $\sim 111 \mathrm{Mb}\left(\operatorname{LOD}_{\text {int }}=9.6\right)$. SIRT2 regulates cardiac homeostasis and remodeling through activation of AMP-activated protein kinase (AMPK) and repression of the nuclear factor of activated Tcells (NFAT), playing a protective role in the heart $(75,76)$. 
bioRxiv preprint doi: https://doi.org/10.1101/2020.08.28.272260; this version posted April 21, 2021. The copyright holder for this preprint (which

was not certified by peer review) is the author/funder, who has granted bioRxiv a license to display the preprint in perpetuity. It is made available under aCC-BY-NC-ND 4.0 International license.

\section{Genomic hotspots for age-interactive eQTL and pQTL}

A

\section{eQTLS}

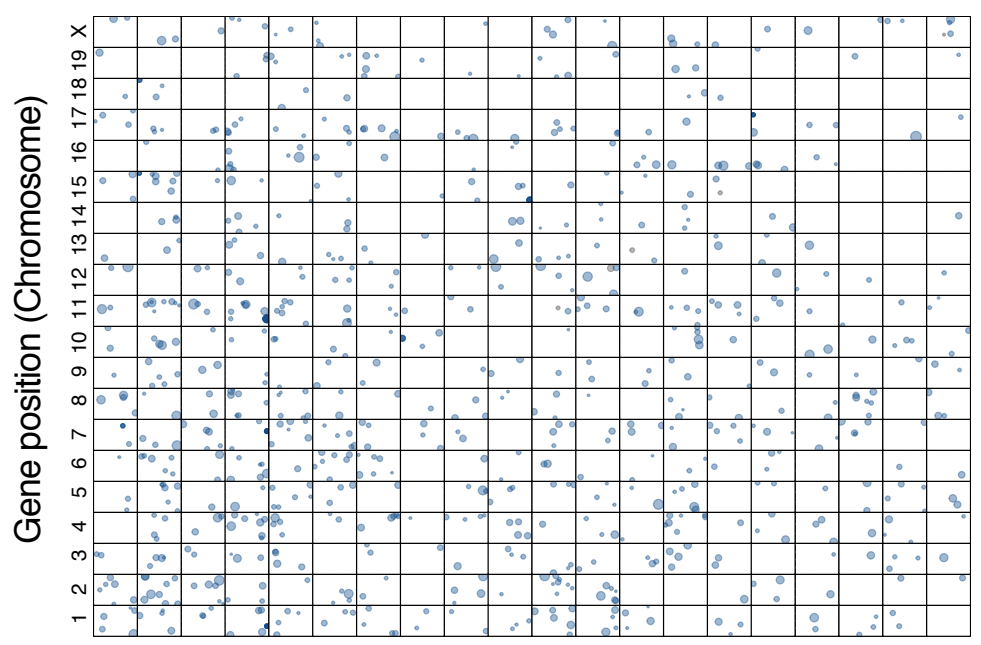

QTL position (Chromosome)

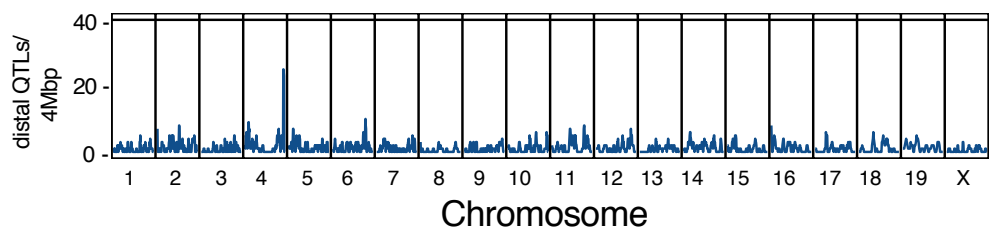

B

pQTLS

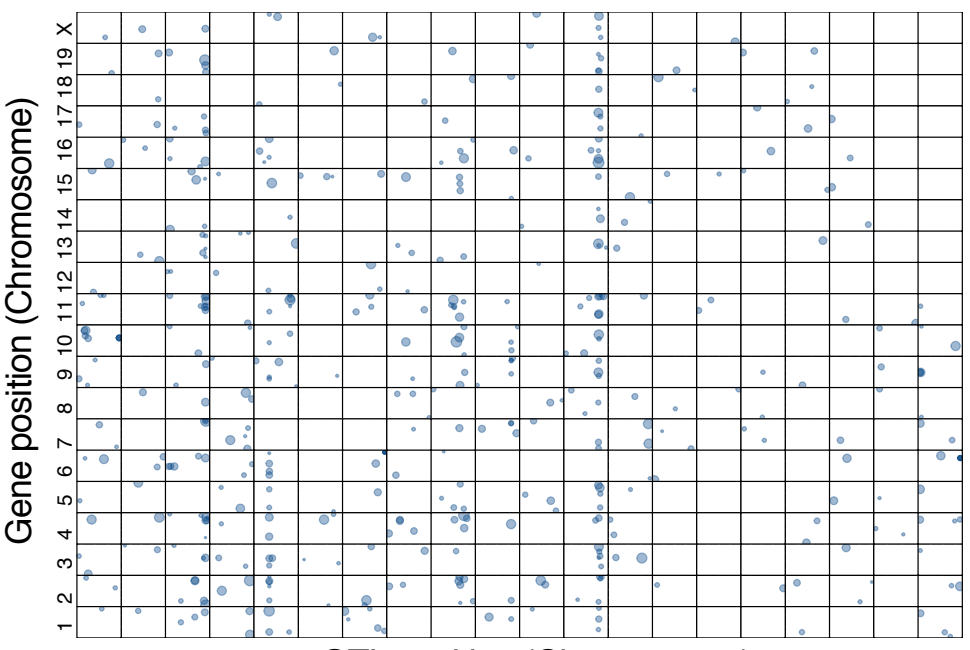

QTL position (Chromosome)

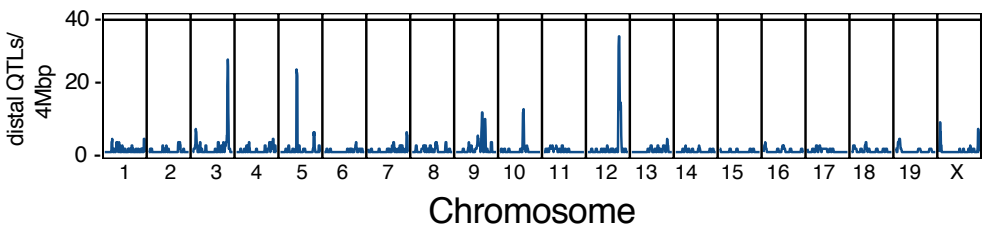

Figure 7. Genomic hotspots for age-interactive eQTL and pQTL. Age-QTL identify the genetic loci involved in ageby-genotype interactions that alter the aging trajectories of transcript (A) or protein (B). In the upper panels in A) and $B$ ) points indicate the location of the QTL peak (x-axis) and the location of the coding gene ( $y$-axis) for significant age-QTL ( LOD $_{\text {int }}>$ 7.75). The lower panels show the number of age-QTL detected in $4 \mathrm{Mb}$ windows along the genome. Most age-QTL are distant from the coding gene. Age-QTL can occur in clusters or hotspots where a single genetic locus interacts with many transcripts or proteins. Hotspots can be seen as vertical bands in the upper panels and as peaks in the density plot of age-QTL shown in the lower panels. 
Many of the age-QTL co-locate to the genome in hotspots (Figure 7). We identified an age-eQTL hotspot on chromosome 4 and three age-pQTL hotspots on chromosomes 3, 5 and 12, respectively (Methods). Genome-wide significant age-QTL meet stringent statistical criteria that can result in missing weaker but biologically relevant age-QTL. Therefore, at each hotspot, we also considered transcripts or proteins with suggestive QTL ( $\left.L O D_{\text {int }}>6\right)$. We then computed the correlation of all candidate transcripts or proteins within each hotspot and retained only those with absolute mean correlation greater than 0.3. This filter removed genes with age-QTL that are not tightly correlated with other genes at the hotspot and thus less likely to share common genetic regulators. For the age-eQTL hotspot on chromosomes 4, none of the transcripts met this criterion suggesting that the hotspot genes are regulated by multiple independent genetic variants. However, all three age-pQTL hotspots included highly correlated proteins, with 167 at the chromosome 3 locus, 130 at the chromosome 5 locus, and 177 proteins at the chromosome 12 locus (Figure 7 - figure supplement 1; Supplementary File 4).

To determine if the proteins that map to the age-pQTL hotspots share common biological functions, we performed enrichment analysis. The proteins in the chromosome 3 hotspot are enriched (FDR < 0.05) for genes in the proteasome complex, including one protein from the core particle (PSMA family) and several proteins from the regulatory particle (PSMC and PSMD families), including PSDM11 and PSMD14, which are the proteins most affected by age in our correlation analysis (Figure 6D2). Proteins that mapped to the hotspot on chromosome 3 are also involved in the myosin filament, including MYH6 and MYH3 that are responsible for muscle cell structure; and the nucleosome, which is composed of the histone families $\mathrm{H} 1, \mathrm{H} 2$ and $\mathrm{H} 3$ (Figure 8A). The proteins that mapped to the chromosome 5 hotspot are associated with 24 enriched GO categories (FDR < 0.05). The two most significant are the endoplasmic reticulum lumen, composed of proteins of the endoplasmic reticulum stress response, such as PDIA4, HSPA5 and HSP9B1, and the contractile fiber containing proteins associated with the muscle contraction apparatus, such as Titin and Desmin (Figure 8B). Finally, for the chromosome 12 hotspot, we found more than $40 \mathrm{GO}$ categories (FDR $<0.05$ ), the most significant of which is muscle contraction that includes proteins related to muscle cell organization, such as myosins and actin, as well as proteins involved in calcium transportation (CACNA2D1) and mitochondria energy generation (NDUFS6) (Figure 8C). Another significant category at the chromosome 12 hotspot is non-coding RNA (ncRNA) transcription, which is associated with chromatin organization, and includes histone $\mathrm{H} 2$ family members and a histone chaperone (NPM1) (Figure 8C). 


\section{Enriched pathways for proteins in the age-pQTL hotspots}

A

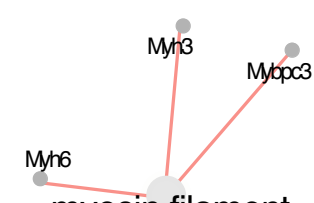

myosin filament
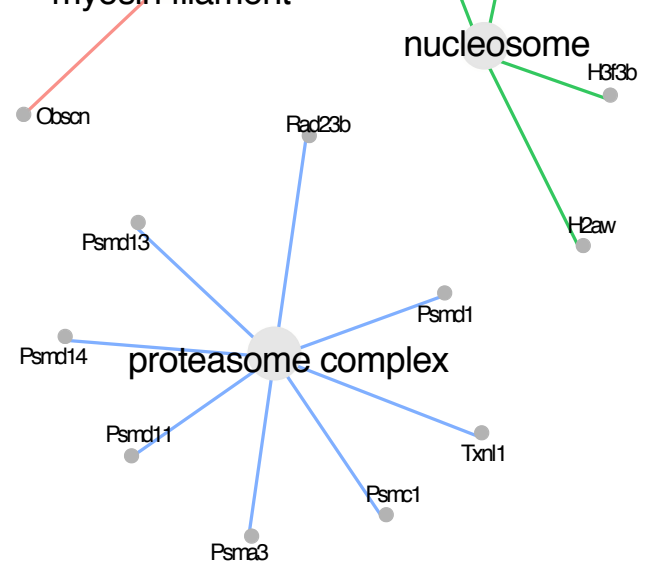

B

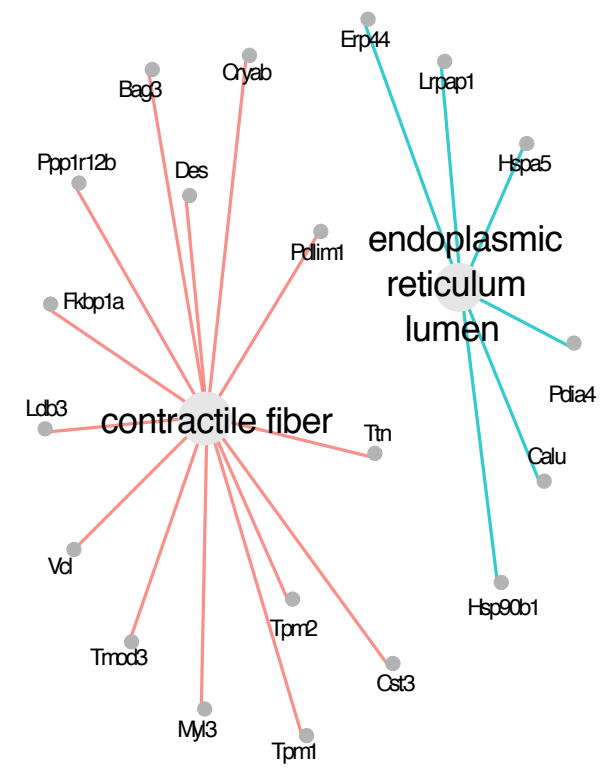

C

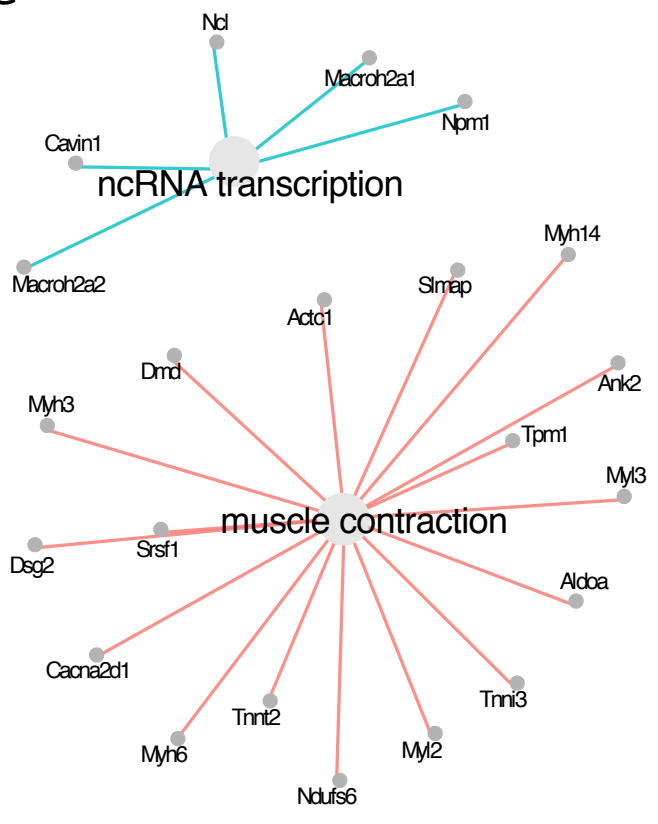

Figure 8. Enriched pathways for proteins in the age-pQTL hotspots. Top enriched GO categories for proteins mapping to the age-pQTLs hotspots are shown. The three hotspot regions regulate proteins involved in distinct biological processes. Proteins that map to the chromosome 3 hotspot (A) are primarily associated with myosin filament, nucleosome and proteasome complex, while proteins that map to the chromosome 5 hotspot (B) participate in contractile fiber and endoplasmic reticulum lumen. Proteins that map to the chromosome 12 hotspot (C) are associated with muscle contraction and ncRNA-transcription. 
To investigate how changes in protein abundance with age can vary due to genetic factors, we estimated the age-effects attributable to each DO founder allele by fitting a regression of the first principal component (PC 1) of the hotspot proteins onto the hotspot genotypes of the DO mice (Figure 9). Each hotspot had a distinct pattern of founder allele effects. For the hotspot on chromosome 3, the effects of the B6 and PWK alleles exhibit opposing trends with age (Figure 9A). For chromosome 5, the effect of the AJ allele on protein abundance shows a pronounced trend with age that is not seen for the other founder alleles (Figure 9B). At the chromosome 12 hotspot, the 129 and NOD alleles have larger effects with increasing age but in opposite directions (Figure 9C).

We confirmed that the allele effects for individual hotspot proteins correspond to the estimates based on PC1 but note that some proteins are negatively correlated with PC1 and have opposite direction of change with age (Figure 9). The chromosome 3 hotspot includes members of the histone families (H2AFY and H3F3B), that participate in chromatin structuring and are positively correlated (Supplementary File 4). For these proteins, B6, CAST or WSB alleles drive decreasing abundance with age, while the PWK allele is associated with increasing abundance with age (Figure 9A).

Chromosome 5 hotspot proteins HSPA5 and PDIA4 participate in the physiological endoplasmic reticulum (ER) stress response and are positively correlated and, for mice with the AJ allele, increases with age (Supplementary File 4). Whereas TTN, a protein responsible for sarcomere structuring and muscle contraction, is negatively correlated and, for mice with the AJ allele, TTN abundance decreases with age (Figure 9B).

Proteins related to chromatin structure, including H2AFY, H2AFY2 and NPM1 are found in the chromosome 12 hotspot. Interestingly, H2AFY also mapped to the chromosome 3 hotpsot. The histone proteins, $\mathrm{H} 2 \mathrm{AFY}$ and $\mathrm{H} 2 \mathrm{AFY} 2$, are positively correlated and, for mice carrying the 129 , decrease in abundance with age. The protein NPM1, which encodes a histone chaperone, is negatively correlated to both H2AFY and H2AFY2, and shows opposite allele effects (Figure 9C).

The QTL hotspots identify loci where genetic variation that presumably acts on gene(s) local to the hotpot, influences multiple proteins with distant coding genes. Therefore, we looked for genes within the QTL support intervals of the hotspots that could be the genetic drivers. Contiguous to the hotspot on chromosome 3 ( $\sim 145-150 \mathrm{Mb})$, we identified a suggestive local pQTL $\left(\right.$ LOD $\left._{\text {int }}=7.01\right)$ for the protein SH3GLB1, also known as BIF-1. The gene is located between $144.68-144.72 \mathrm{Mb}$ and has an age-bygenotype allele effects pattern similar to the PC 1 allele effects (Figure 9A), consistent with a shared 
genetic driver and, given the genomic location of SH3GLB1, consistent with the hypothesis that SH3GLB1 modulates the proteins that mapped to the chromosome 3 hotspot. We note that BIF-1 plays a role in autophagy regulation $(77,78)$, an important component of protein quality control system that declines with age (79). We propose BIF-1 as positional candidate driver of the age-related changes in proteins that mapped to the chromosome 3 hotspot. Examination of the chromosome 5 and chromosome 12 hotspot regions did not identify any strong candidate genes. 
bioRxiv preprint doi: https://doi.org/10.1101/2020.08.28.272260; this version posted April 21, 2021. The copyright holder for this preprint (which was not certified by peer review) is the author/funder, who has granted bioRxiv a license to display the preprint in perpetuity. It is made available under aCC-BY-NC-ND 4.0 International license.

\section{Allele effects on protein abundance at age-pQTL hotspots}

A

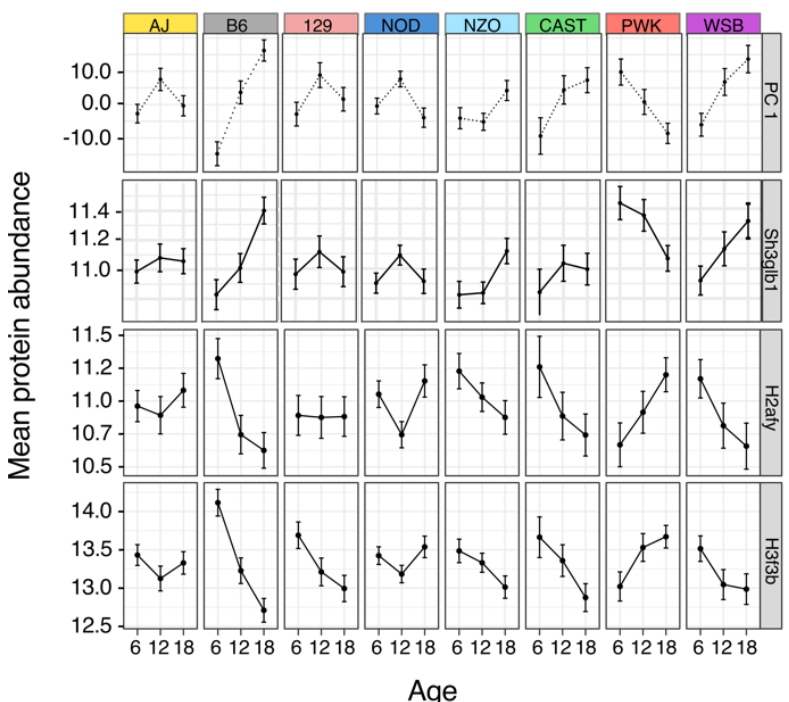

B

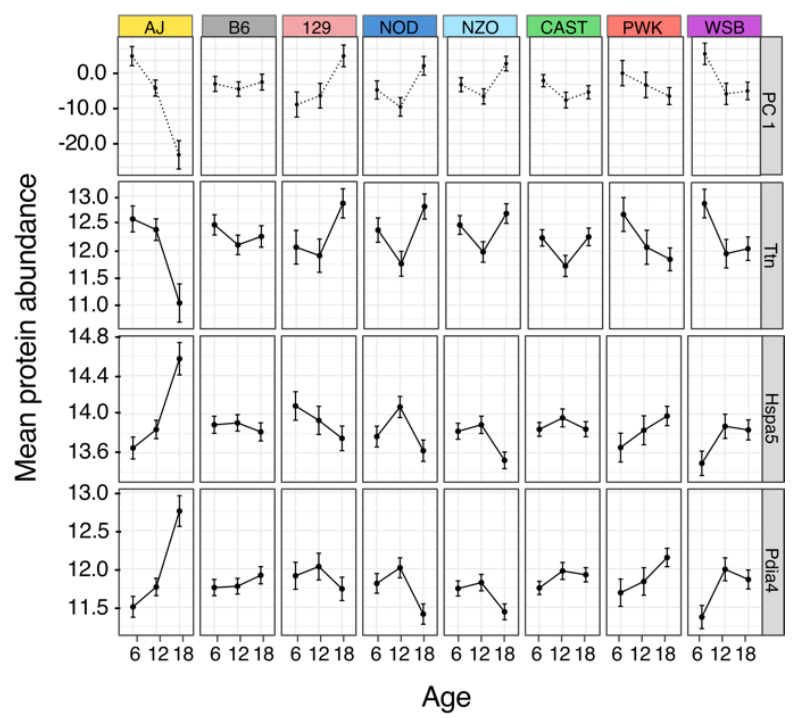

C

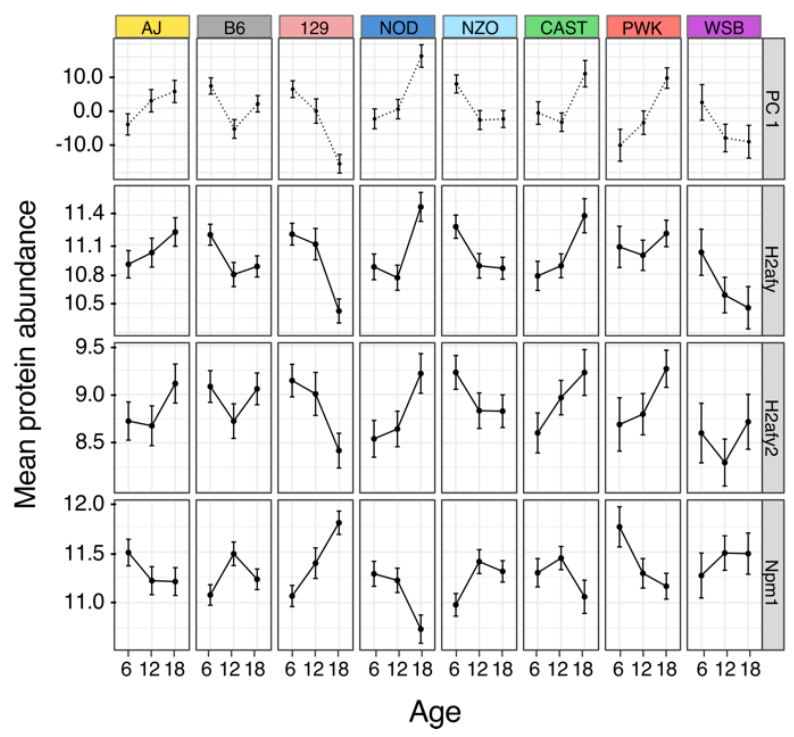

Figure 9. Allele effects on protein abundance at age-pQTL hotspots. Protein abundances associated with DO founder alleles at age-QTL hotspots were estimated for each age group. Estimates are shown for the first principal component (PC 1) of all proteins in the hotspot and for selected individual proteins. Error bars denote +/- 1 SE. Protein SH3GLB1, also known as BIF-1, is located near the hotspot on chromosome 3, and it is positively correlated to $P C 1$ (A). Proteins H2AFY and H3F3B, in the same hotspot, participate in the nucleosome complex, and are negatively correlated with PC 1 , showing inverted allele-specific patterns of change with age (A). HSPA5 and PDIA4, in the chromosome 5 hotspot, participate in the endoplasmic reticulum stress response. These proteins are negatively correlated to PC 1 and show similar allele effect patterns (B). Another chromosome 5 hotspot protein, TTN, which is involved in sarcomere structure, shows opposite allele effects with age (B). H2AFY and H2AFY2, associated with chromatin structuring, mapped to the chromosome 12 hotspot, are positively correlated to PC 1 , and share similar allele effect patterns (C). The protein NPM1, also involved in chromatin structure as a histone chaperone, shows inverted allele effects with age (C). 


\section{DISCUSSION}

By analyzing both transcripts and proteins in the mouse heart we were able to detect distinct biological processes that are altered through the course of natural aging. We and others have found that age-related transcriptional changes are not necessarily followed by a change in their proteins and likewise, age-related changes in proteins are not preceded by transcriptional changes $(12,13,62,80)$. We found that transcripts decreasing in expression with age are associated with cardiomyocyte contraction and survival, and fatty-acid metabolism. These findings are consistent with previous reports describing disrupted Ca2+ handling, progressive loss of myocytes, and metabolism switch in the aging heart, which may reflect a compensatory mechanism to improve contractility $(3,4,81)$. Transcripts increasing in expression with age are involved in the acute-phase response and cardiac fibrosis, which suggest chronic inflammation and loss of cardiomyocytes that stimulate extracellular matrix remodeling during the aging process (82-84).

Proteomics reveals major features of the aging heart that are not detected at the transcript level. We saw changes in mitochondrial respiratory chain proteins, as well as intracellular protein and vesicular transport pathways, in agreement with previous proteome analysis of the aging mouse heart $(85,86)$. We observed that most of the proteins from the RAB and AKT families increase their abundance with age, suggesting growth of cardiomyocytes and increased cellular synthesis, which is commonly observed in hypertrophic hearts (1). Proteins of the mitochondrial respiratory complexes II, III and IV increase with age while proteins from Complex I change in both directions. This increase in proteins across most of the mitochondrial complexes could act as a compensatory mechanism in response to an input deficiency from early steps in oxidative phosphorylation.

We found that ACTN3, which is involved in the structuring of sarcomeric $Z$ line and the regulation of the contraction apparatus, decreases with age. Actn3 expression has been observed in the skeletal muscle, but has not been reported previously in the heart of either mice or humans (87). In knockout mice, the deficiency of ACTN3 in the skeletal muscle promotes a switch from fast-anaerobic metabolism towards a more efficient aerobic metabolism, leading to better exercise performance $(58,59)$. The same study also speculated that the Actn3 null allele has been under positive selection in modern humans, suggesting that aerobic metabolism boosting may confer a fitness advantage (59). In humans, ACTN2 and ACTN3 appear to have functional redundancy, and Actn2 was recently linked to heart failure in a multi-omic analysis $(87,88)$. Our data suggests that ACTN3 may participate in the regulation of metabolic efficiency not only in the skeletal muscle, but also in the mouse heart, and might contribute to the physiological changes in muscle efficiency during the aging process. 
We observed that proteins associated with fetal metabolism increase with age. A return to embryo/fetal gene program occurs in some pathological heart conditions and it is thought to play a protective role $(89,90)$. The fetal heart is under constant stress conditions, including hemo-dynamic load and hypoxia, and uses carbohydrates as a primary energy source to maintain cardiac efficiency $(89,91)$. The aging heart undergoes different types of stress including the accumulation of reactive oxygen species, cardiomyocyte loss, mitochondrial dysfunction and hypoxia $(81,92)$. These stressors are even more pronounced when they co-occur with other age-related comorbidities, such as diabetes mellitus and hypertension. Studies have demonstrated a return to the fetal gene program in diabetic rats with cardiac diseases $(93,94)$. We propose that a return to the fetal program happens in mice during the normal aging process and may play an adaptive role to compensate for age-related decline in other biological functions of the heart.

The protein data suggest age-related changes in the stoichiometry between members of protein complexes. In general, the correlations between proteins within complexes decrease with age. In contrast, correlations at the transcript level tended to increase with age, although these effects were less pronounced. This dynamic suggests that stochiometric regulation in protein complexes is largely posttranscriptional. These observations are consistent with previous studies that have shown that the production of protein complex subunits is not always perfectly stoichiometric and post-translational mechanisms play an essential role in removing extra subunits and promoting the balance of these complexes (61). Here, in concordance with previous findings using different organisms and tissues $(62,63)$, we propose an age-related loss of stoichiometry across multiple protein complexes, including the mitochondrial respiratory chain complexes, and complexes related to the protein quality control system, notably including the $26 \mathrm{~S}$ proteasome. Taken together, these findings suggest that age-related protein complexes accumulate stoichiometric imbalance during the aging process.

The proteasome plays a crucial role in regulating the abundance and stoichiometry of proteins in the cell (95), and several studies have attempted to understand why proteasome activity declines with age (96-98). One hypothesis is that reduced expression of proteasome subunits can lead to the decline of proteasome activity in the heart, however, disruption in protein degradation was already observed without reduction in proteasome abundance (98). In this work, we did not observe a reduction in the expression of proteasome subunits, in fact, most of them increase with age (Supplementary File 1; Supplementary File 2). It also has been proposed that post-translational modifications and the excess of oxidized proteins contribute to the decline in proteasome activity in the heart $(98,99)$. Here, supported by 
previous findings $(62,63)$, we propose that age disrupts the balance of proteasome subunits in the heart, which potentially contributes to a vicious cycle of progressive protein quality control breakdown during the aging process.

For the first time, we found that genetic variation can modulate the dynamics of proteins involved in protein quality control. Most age-QTLs are distant, indicating that genetic variation is not primarily acting on proximal genes, which supports the importance of post-transcriptional mechanisms in regulating protein homeostasis during aging $(11,13)$. Proteins that map to the hotspot loci are functionally related and many have established roles in aging.

Proteins that map to hotspots on chromosomes 3 and 5 are enriched for functions in the proteasome complex and endoplasmic reticulum (ER) lumen, respectively (Figure 8A/B). Proteosome complex proteins PSMD13 and PSMD14 that were also implicated in the loss of stoichiometry (Figure 6D2). These findings suggest that genetic variation can potentially affect the stoichiometry of the proteasome complex. Both the ER and the proteasome complex are part of the protein quality control system that coordinates proteostasis and cell survival (100). The ER contains transmembrane proteins that sense the presence of misfolded proteins, which then activates transcription factors that up-regulate the expression of ER stress response genes (100). Some misfolded proteins are marked by ubiquitination and transferred to the cytosol, where they are degraded by the proteasome complex (100). The proteins HSPA5, HSP90B1 and PDIA4, present in the chromosome 5 hotspot (Figure 8B), are known to be downstream targets of the ATF6 branch of the ER unfolded protein response and this pathway was found to be adaptive and cardioprotective in several studies (101-104).

Enrichment analysis of the hotspots on chromosomes 3 and 12 identified proteins associated with chromatin structure (Figure $8 \mathrm{~A} / \mathrm{C}$ ), including histones and histones chaperones, such as NCL and NPM1 (Figure 8C). Loss of chromatin structure was previously reported in aging models for yeast and human fibroblasts $(105,106)$, and leads to dysregulation of global gene expression, increased genomic instability, and promiscuous access of DNA damaging agents to the chromatin $(107,108)$. It is interesting to note that all histone proteins in our data decrease with age (Supplementary File 2), suggesting that age-related loss of chromatin structure also occurs in the heart.

We identified the protein SH3GLB1 (BIF-1) as a potential driver of the age-related dynamics of proteins that mapped at the chromosome 3 hotspot. SH3GLB1 is a member of endophilin protein family that plays a role in mitochondrial fission, vesicle formation and autophagy $(77,109,110)$. As mentioned 
earlier, the protein quality control system contributes to the aging process and studies suggest that increased autophagy may be a compensatory effect when the proteasome complex is disrupted $(111,112)$. In addition, autophagy plays an important role in maintaining chromosomal stability, and loss of Sh3glb1 was shown to induce DNA damage due to metabolic stress (113). Autophagy is crucial for maintaining cardiac function - mice with disrupted autophagy show anomalies in sarcomere and mitochondria structure (114). Our findings suggest that genetic variation in the DO mice, near the Sh3glb1 locus, influences individual rates of change with age of proteins involved in the proteasome complex, chromatin structuring and muscle apparatus organization.

In summary, we have described changes that occur with normal aging in heart tissue from DO mice that suggest a scenario of mitochondrial dysfunction, physiological hypertrophy, and a return to the fetal gene expression program. The proteome data revealed aspects of aging in the heart that are not seen at the transcript level, including the loss of stoichiometry within protein complexes involved in protein trafficking and sorting. We found that genetic variation can influence the age-related dynamics of members of the protein quality control system and other biological processes that play a role in aging. These genetic effects are distal and complex, likely acting through a gene or set of genes near the hotspot locus that indirectly modulates the expression of functionally related groups of proteins. Our findings illustrate how transcriptome and proteome profiling data collected in a genetically diverse model system can reveal broad patterns of change in the molecular dynamics of the aging heart.

\section{MATERIAL AND METHODS}

\section{Study cohort and tissue collection}

The cross-sectional aging study was initiated with 600 DO mice (300 of each sex) bred at The Jackson Laboratory (stock no. 009376) across five waves representing breeding generations 8 through 12 of the DO stock. Mice were maintained on a standard rodent chow (LabDiet 5K52, St. Louis, MO) in an animal room that was free of pathogens, had a set temperature ranging from $20-22^{\circ} \mathrm{C}$, and a 12 -hour light/dark cycle. The full study was populated across 6 generations of DO breeding over a period of two years. Animals were housed at 4 mice per pen and pens were randomly assigned to 6,12 , and 18 monthaged groups for tissue collection. Whole hearts were dissected, flash-frozen, pulverized and aliquoted. A subset of 192 samples, balanced across age groups and sexes were selected for RNA-seq and shotgun 
mass spectrometry. This set included 34 females and 30 males at age 6 months, 31 females and males at age 12 months, and 31 females and 35 males at age 18 months. The representation of generational waves included 43 mice from generation 8, 35 mice from generation 9, 38 mice from generation 10, 39 mice from generation 11, and 37 mice from generation 12. The mass spectrometry was performed for 190 of the 192 mice ( 1 female and 1 male in the 12 months were not included). The Jackson Laboratory Institutional Animal Care and Use Committee approved all procedures used in this study.

\section{Sample size determination}

The sample size required to detect a significant age effect is determined by the expected size of the effect (difference in means between the 6-and 18-month age groups) relative to the within age-group variance. Therefore, we define the strength of an effect in units of standard deviation (SD) of the within group variance. Based on standard power calculations (115), with a sample size of 64 animals per age group we can expect to achieve power $=0.80$ to detect an age effect of $0.5 \mathrm{SD}$ at an unadjusted type I error of 0.05 . In practice, because of the high precision of the RNA and protein quantification, this enabled us to detect age effects in the majority of genes tested even after applying a false discovery error rate correction for multiple testing (116). To evaluate the power for genetic mapping, we referred to simulations conducted by Gatti et al. (2014) (117). After applying family-wise error rate for multiple testing of the genome-scan, our sample of 188 animals has expected power $=0.80$ to detect a QTL that explain $20 \%$ of the total variation in RNA or protein expression.

\section{Bulk RNA extraction}

The frozen and pulverized heart tissue was lysed in Ambion TRIzol reagent (Thermo Fisher Scientific \#15596026, Waltham, Massachusetts). Bulk RNA was isolated using the miRNeasy Mini kit (Qiagen Inc. \#217004, Germantown, MD), according to the manufacture's protocols with the DNase digest step. RNA concentration and quality ratios were assessed using the Nanodrop 2000 spectrophotometer (Thermo Fisher Scientific) and RNA 600 Nano LabChip assay (Aligent Technologies, Santa Clara, CA).

\section{RNA sequencing and quantification}


Poly(A) RNA-seq libraries were generated using the TruSeq Stranded mRNA Library Prep Kit (Illumina, San Diego, CA). Libraries were pooled and sequenced 100 bp single-end on the HiSeq 2500 (Illumina) using TruSeq SBS Kit v4 reagents (Illumina). The RNA-seq experiment was performed in two replicates for each sample distributed across 8 lanes. The replicates of each sample were carried out in different lanes to avoid lane effects.

Expectation-Maximization algorithm for Allele Specific Expression (EMASE) was used to quantify multi-parent allele-specific and total expression from RNA-seq data (118) using the Genotype by RNA-seq (GBRS) software package (https://gbrs.readthedocs.io/en/latest/) (RRID:SCR_020963). Transcripts were removed if they did not have at least one read in at least half of the samples, resulting in a total of 20,932 transcripts for further analysis. RNA-Seq counts were normalized relative to total read counts using the variance stabilizing transform (VST) as implemented in DESeq2 (RRID:SCR_015687) (28). For the genetic mapping analysis only, in order to minimize the impact of outliers, we transformed the vst normalized data to rank normal scores (119).

\section{Mass spectrometry and protein quantification}

Mass spectrometry (MS) experiment and protein quantification were performed as described in Chick et al. (2016) (69). In summary, tissue from the total heart samples were homogenized in $1 \mathrm{ml}$ lysis buffer, which consisted of 1\% SDS, $50 \mathrm{mM}$ Tris, pH 8.8 and Roche complete protease inhibitor cocktail (Roche \# 11697498001, Clifton, NJ). Peptide measurements were performed using Tandem Mass Tags (TMT) and carried out in batches of 10 samples each. MS spectra assignments were made using the Sequest algorithm (120) with the Ensembl database (mouse: Mus_musculus NCBIM37.61), and protein abundances were estimated from their component peptides. Samples were assigned to batches in randomized order. Sample labels were not masked and there were no technical replications performed.

Prior to protein abundance estimation, we filtered out peptides that contained polymorphisms in DO mice relative to the mouse reference genome in order to minimize false PQTL signals that can occur due to failure to detect polymorphic peptides. To estimate and normalize protein abundance from component peptides, we followed Huttlin et al. (2010) (121) and calculated: 


$$
\operatorname{Protein}_{i j}=\log _{2}\left(\frac{\sum_{K} \text { Peptide }_{i k}}{s_{i}}+1\right)
$$

where $K$ represents the set of observed peptides that map to protein $j$ for mouse $i$ and $s_{i}$ is a scaling factor for standardizing samples within a batch. $s_{i}=\frac{\sum_{L} \text { Peptide }_{i l}}{\max \left(\sum_{L} \text { Peptide }\left._{q l}\right|_{q \in b[i]}\right)}$, where $L$ is the set of all peptides observed for a sample, $b[i]$ denotes the batch of sample $i$, and $\max \left(\sum_{L} \operatorname{Peptide}_{q l}: Q \in b[i]\right)$ is the maximum sum of peptides for all the samples in batch $b[i]$. Protein abundance levels that were missing (NA) were imputed to be zero. Proteins with zeros for more than half the samples were excluded, resulting in a total of 4,062 proteins for further analysis.

The MS experiment was performed in batches of 10 samples processed and quantified simultaneously. Batch effects were removed using a linear mixed effect model (LMM) fit with the Ime4 package (RRID:SCR_015654) (122). The batch effect, estimated as a best linear unbiased predictor (BLUP), was subtracted from each protein abundance, while age (as a categorical variable with three levels) and sex were included as fixed effect covariates in the model. For genetic mapping analysis, protein abundances were transformed to rank normal scores to minimize the effect of outliers (119).

\section{Age effect on transcript expression}

We used the DESeq2 package (28) to test for transcripts whose expression changed with age. Briefly, we fit the following GLM using the negative binomial distribution in DESeq2:

Equation 2

$$
\operatorname{Transcript}_{i}=\operatorname{Sex}[i]+\operatorname{Gen}[i]+\operatorname{Age}[i]
$$

where Transcript $_{i}$ is the total count for each transcript from mouse $i, \operatorname{Sex}[i]$ is the effect corresponding to the sex of mouse $i, \operatorname{Gen}[i]$ is the effect corresponding to the generation of mouse $i$, and Age $[i]$ is the effect corresponding to the age of mouse $i$, fit as a continuous variable at the year scale $(0.5,1,1.5$ years) obtained by dividing the age groups by 12 . The age effect was tested using its Wald statistic and it estimates the $\log _{2}$ fold change per year of life. Transcripts with a significant age effect on expression were determined after FDR adjustment to account for multiple testing across all transcripts (FDR $<0.1$ ).

\section{Age effect on protein abundance}


To detect proteins with age effects, we fit a log-normal linear model with predictors similar to Equation 2:

Equation 3

$$
\operatorname{Protein}_{i}=\operatorname{Sex}[i]+\operatorname{Gen}[i]+\operatorname{Age}[i]+\varepsilon_{i}
$$

where $\operatorname{Protein}_{i}$ is the log-scale abundance of each protein from mouse $i$, as defined in Equation $1, \varepsilon_{i}$ is the residual, and all other terms as previously defined. The age effect corresponds to the slope of the regression model and it estimates the $\log _{2}$ fold change per year of life. Proteins with significant age effects were identified after FDR adjustment $($ FDR $<0.05)$.

\section{Age effect in the correlation of genes coding for protein complexes}

To investigate the stoichiometry of protein complexes (64) (CORUM database) we adapted a method described in McKenzie et al (2016) (65). We computed the Pearson correlation between the expression of each gene-pair in the protein complexes for both transcript and protein data and for each age group. Then for each protein complex and data type (transcript and protein), we regressed the correlation coefficients of each gene-pair on age and recorded the slope, which represents the age effect, in units of change in correlation per year, as in Equation 4:

Equation 4

$$
\text { Correlation }_{k}^{i, j}=\text { intercept }+ \text { Age }[k]+\varepsilon_{k}
$$

where Correlation ${ }_{k}^{i, j}$ is the correlation between proteins $i$ and $j$ at age $k$, intercept is the overall intercept, $A g e$ is the age effect, fit from a continuous encoding of age at the year scale, $A g e[k]=\beta_{A g e} *$ $k$, and $\varepsilon_{k}$ is the residual at age $k$. In order to determine significance, we shuffled the mouse IDs and repeated the slope estimation 1,000 times to obtain FDR estimates using the DGCA package (RRID:SCR_020964) (65). Significant age effects were declared at FDR $<0.1$.

We also fit a model to compute the overall age effect for each protein complex, without fitting separate models per gene-pair. We fit a linear mixed model using the R/Ime4 package to jointly model gene-pairs with a random effect, allowing the intercept and age slope for each gene-pair:

Equation 5

$$
\text { Correlation }_{i j k}=\mu+u[i j]+\left(\beta_{\text {Age }}+v_{\text {Age }}[i j]\right) x_{k}+\varepsilon_{i j k}
$$


where Correlation $_{i j k}$ is the correlation between proteins $i$ and $j$ at age $k, \mu$ is the overall intercept, $u[i j]$ is the random deviation on the intercept specific to the pairing of proteins $i$ and $j, \beta_{\text {Age }}$ is the overall age effect, $v_{\mathrm{Age}}[i j]$ is the random deviation on the age effect specific to the paring of proteins $i$ and $j, x_{k}$ is the age $\left(6,12\right.$, or 18 months), and $\varepsilon_{i j k}$ is random noise on the correlation for proteins $i$ and $j$ at age $x_{k}$. The protein pair-specific random terms are modeled as $\mathbf{u} \sim \mathrm{N}\left(\mathbf{0}, \mathbf{I} \tau^{2}\right)$ and $\mathbf{v}_{\text {Age }} \sim \mathrm{N}\left(\mathbf{0}, \mathbf{I} \tau_{\text {Age }}^{2}\right)$, and the error as $\varepsilon_{i j k} \sim \mathrm{N}\left(\mathbf{0}, \mathrm{I} \sigma^{2}\right)$. We used the permutations procedure from McKenzie et al (2016) (65) to determine significance, using a $p$-value cut-off of 0.05 , for each protein complex.

\section{Additive QTL mapping}

Although the results of additive QTL mapping are not reported here, it is useful to describe the methods used as a prelude to the description of age-interactive QTL mapping analysis. For each transcript or protein, we transformed the data to rank-normal scores (119) and fit the following model at 64,000 equally spaced loci across the genome:

Equation 6

$$
\mathrm{y}_{i j}=\mathrm{QTL}_{m}[\mathrm{i}]+\operatorname{Sex}[i]+\operatorname{Age}[i]+u_{m i j}+\varepsilon_{i j}
$$

where $y_{i j}$ is the transcript or protein $j$ expression/abundance for mouse $i, \mathrm{QTL}_{m}[\mathrm{i}]$ is the expected dosage of founder haplotype alleles for mouse $i$ at locus $m, u_{m i j}$ is a random kinship effect that accounts for the correlation between individual DO mice due to shared genetic effects excluding the chromosome of locus $m$. The kinship effect is modeled as $\mathbf{u} \sim \mathrm{N}\left(\mathbf{0}, \mathbf{K} \tau_{\mathrm{K}}^{2}\right)$, where $\mathbf{K}$ is a realized genomic relationship matrix and $\tau_{\mathrm{K}}^{2}$ is the variance component underlying the kinship effect (123). The $\log _{10}$ likelihood ratio (LOD score) was determined by comparing the QTL model (Equation 4) to the null model without the QTL term.

\section{Age-interactive QTL mapping}

We performed a second set of genome scans to identify age-interactive QTL loci where the rate of change of a transcript or protein is dependent on genotype. Genome scans for age-QTL are based on the following model:

Equation 7

$$
\mathrm{y}_{i j}=\mathrm{QTL}_{m[\mathrm{i}]} \times \operatorname{Age}[\mathrm{i}]+\mathrm{QTL}_{m}[\mathrm{i}]+\operatorname{Sex}[i]+\operatorname{Age}[i]+u_{m i j}+\varepsilon_{i j}
$$


where $\mathrm{QTL}_{m[i]} \times \mathrm{Age}[\mathrm{i}]$ is the interaction effect between the QTL genotype and age of mouse $i$. All other terms are as previously defined. The null model for the age-interactive genome scans is the model from Equation 6, thus only the interaction term is being tested. To determine significance thresholds for ageQTL we required a more elaborate permutation procedure than the standard used for additive QTL (124). For each transcript or protein, we fit the following model:

Equation 8

$$
\mathrm{y}_{i j}=\operatorname{Sex}[i]+\operatorname{Age}[i]+u_{i j}+\varepsilon_{i j}
$$

Where the kinship term $u_{i j}$ includes effects of all loci, including the additive effect of the locus under evaluation. We then computed the residuals by subtracting the fitted values of model predictors:

Equation 7

$$
\left.\mathrm{e}_{i j}=\mathrm{y}_{i j}-\widehat{\operatorname{Sex}[\mathrm{i}}\right]+\widehat{\operatorname{Age}[\mathrm{i}]}+\widehat{u_{l j}}
$$

To construct a permutation test, we generate null data by summing the fitted effect values with a randomly permutated of the residuals from Equation 7. We repeated the age-interactive scans on the residual-permuted phenotypes 1000 times to obtain a null distribution sample of the $\operatorname{LOD}_{\text {int }}$ statistic. Signficance thresholds for the maximum $\operatorname{LOD}_{\text {int }}$ scores were based on the 95th percentile of this distribution and a suggestive threshold was determined using the $37^{\text {th }}$ percentile. Transcript and protein age-QTLs were considered significant when $\operatorname{LOD}_{\text {int }}>7.75$ and suggestive when $\operatorname{LOD}_{\text {int }}>6.0$. All QTL analyses were performed with the R/qt12 package (RRID:SCR_020965) (125).

\section{Distal QTL hotspot analysis}

Using a sliding window of $4 \mathrm{Mb}$, we counted the density of suggestive age-QTL $\left(\operatorname{LOD}_{\text {int }}>6\right)$ for transcripts and proteins (Figure 7). We defined a genomic region as a hotspot based on having more than 40 age-QTLs. We used the hotspots to defines sets of transcripts and proteins that mapped to these regions. We further refined the hotspot sets by filtering out transcripts or proteins with a mean Pearson correlation coefficient $<0.3$ with the other hotspot members, removing genes that are not highly correlated with other genes that map to the hotspot.

\section{Age-specific allele effects}


Proteins with shared genetic drivers, which could cause distal age-QTL hotspots, should have similar allele effects. To investigate this, we computed the principal components (PCs) from the refined hotspot proteins. We then estimated age-specific allele effects for the first principle component (PC1), and for each protein that mapped to the hotspot, using the function fit1() from R/qt/2 package (125). We fit the model separately to each age group, including sex as an additive covariate, to estimate the agespecific effects associated with each of the eight founder alleles that are present in DO mice.

\section{Functional enrichment analysis}

We performed functional enrichment analysis for transcript and protein gene sets with significant age effects and also to sets of genes in the refined age-QTL hotspots. We used the ClusterProfiler package (RRID:SCR_016884) (26) to identify enriched gene ontology terms (biological processes, cellular compartments and molecular functions) for each set. We used stringent (FDR $<0.05)$ and lenient $($ FDR $<$ 0.1 ) cut-offs to defined enriched categories for reporting.

\section{Software}

All data analysis and figures were generated using R v3.6.0 (RRID:SCR_001905) based on the packages tidyverse v1.3.0 (RRID:SCR_019186) and ggplot2 v3.3.0 (RRID:SCR_014601). The R Scripts used for all the analysis performed on this work can be found on Github ( https://github.com/isabelagyuricza/Aging Heart DO analysis) and on Figshare (DOI: 10.6084/m9.figshare.12430094.v1).

\section{Data access}

The RNA fastq files can be found on on NCBI SRA repository under bioproject PRJNA510989. The mass spectrometry proteomics data have been deposited to the ProteomeXchange Consortium via the PRIDE partner repository (http://www.proteomexchange.org/ - PXD023724). Both raw and normalized transcript expression matrices, as well as the protein abundance data have been deposited to Figshare (10.6084/m9.figshare.12378077). Genotype data is deposited the DODb database (https://dodb.jax.org/). All data and QTL results are available for download and interactive analysis using the QTLViewer for user 
driven queries (https://qtlviewer.jax.org). Raw and normalized quantification of transcripts and proteins and the genotype data are included in the download in a Rdata format suitable for further analysis.

\section{Acknowledgements}

The authors gratefully acknowledge the contribution of Matthew Vincent for creating the QTLViewer web tool. We also thank Heidi Munger and all the staff from the Genome Technology Service at The Jackson Laboratory for expert assistance with the RNA-seq experiments described in this publication. This work was supported by the National Institutes of Health and The Jackson Laboratory Nathan Shock Center of Excellence in the Basic Biology of Aging (P30 AG038070). 


\section{Supplementary material legends}

Figure 5 - figure supplement 1 . Standardized age effects for the expression/abundance of all the subunits from the mitochondrial complexes (I-V) at the transcript ( $x$-axis) and protein ( $y$-axis) levels. Color indicates the significance of the age effect at the transcript level (FDR $<0.1)$, protein level (FDR $<0.05)$, both or neither. For all the complexes, significant age-related changes are predominant at the protein level, and, with exception of mitochondrial complex $V$, they tend to change in both directions. Age effect corresponds to the linear trend with age in units of LFC per year.

Figure 7 - figure supplement 1. Heatmaps for the Pearson correlation coefficients between transcripts or proteins that mapped to the age-QTL hotspots. A) Correlations between transcripts that mapped to the chromosome 4 ageeQTL hotspot show that there is no evidence for correlation in this group of transcripts. B) Correlations between proteins that mapped to the chromosomes 3 (B1), 5 (B2) and 12 (B3) age-pQTLs hotspots identify tightly correlated groups of proteins (positive or negative) that are potentially regulated by shared genetic variation.

Supplementary File 1. List of transcripts with significant age-related changes in expression.

Supplementary File 2. List of proteins with significant age-related changes in abundance.

Supplementary File 3. List of gene-pairs members of protein complexes that have a significant change in their pairwise correlations with age at the transcript or at the protein level.

Supplementary File 4. Annotation of all the suggestive age-eQTLs and age-pQTLs. 


\section{Highlighted transcripts that change with age}

Table 1. Highlighted transcripts that change with age.

\begin{tabular}{|c|c|c|c|}
\hline Transcript symbol & Direction of change & Function highlights & Reference index \\
\hline Adamts1 & Increases & Cardiac fibrosis & (29) \\
\hline Ahsg & Increases & Free fatty-acid signaling & (43) \\
\hline Nov & Increases & Heart development & $(32,33)$ \\
\hline Olfm2 & Increases & $\begin{array}{c}\text { Vascular smooth muscle cell } \\
\text { regulation }\end{array}$ & (126) \\
\hline Serpine1 & Increases & Cardiac fibrosis & $(30,31)$ \\
\hline $\operatorname{Tnfsf11}$ & Increases & Aortic valve calcification & (45) \\
\hline Cacna1g & Decreases & Cardiac muscle contraction & $(127,128)$ \\
\hline Myocd & Decreases & Cardiomyocytes survival & (34) \\
\hline Naca & Decreases & Sarcomere organization & $(129-131)$ \\
\hline Pln & Decreases & Cardiac muscle contraction & (37) \\
\hline Ppara & Decreases & Fatty acid metabolism & $(132-134)$ \\
\hline Stat5b & Decreases & Insulin signaling & $(40,41)$ \\
\hline
\end{tabular}




\section{Highlighted proteins that change with age}

Table 2. Highlighted proteins that change with age.

\begin{tabular}{|c|c|c|c|}
\hline Protein symbol & Direction of change & Function highlights & Reference index \\
\hline AKT1 & Increases & Physiological cardiac growth & $(48,50)$ \\
\hline AKT2 & Increases & Cardiac glucose metabolism & $(48,51)$ \\
\hline COX4I1 & Increases & $\begin{array}{c}\text { Mitochondrial respiratory chain complex IV } \\
\text { cytochrome c subunit }\end{array}$ & $(135)$ \\
\hline NDUFB6 & Increases & $\begin{array}{l}\text { Mitochondrial respiratory chain complex I } \\
\text { subunit }\end{array}$ & $(136,137)$ \\
\hline RABGEF1 & Increases & Mitophagy induction & $(56)$ \\
\hline SDHD & Increases & $\begin{array}{l}\text { Mitochondrial respiratory chain complex III } \\
\text { cytochrome b subunit }\end{array}$ & (138) \\
\hline ACTN3 & Decreases & Muscle anaerobic metabolism & (59) \\
\hline ATP1F1 & Decreases & Inhibition of mitochondrial ATPase activity & $(139,140)$ \\
\hline CRIP2 & Decreases & $\begin{array}{l}\text { Smooth muscle tissue differentiation and } \\
\text { cardiomyocyte survival }\end{array}$ & $(141-143)$ \\
\hline NDUFA1 & Decreases & $\begin{array}{l}\text { Mitochondrial Respiratory Chain Complex I } \\
\text { subunit }\end{array}$ & (144) \\
\hline RAB1B & Decreases & Cardiac hypertrophy & $(145)$ \\
\hline TIMM29 & Decreases & $\begin{array}{l}\text { Translocase of inner mitochondrial } \\
\text { membrane (Complex 22) }\end{array}$ & $(146)$ \\
\hline
\end{tabular}




\section{REFERENCES}

1. Chiao YA, Rabinovitch PS. The aging heart. Cold Spring Harb Perspect Med. 2015 Sep 1;5(9).

2. North BJ, Sinclair DA. The intersection between aging and cardiovascular disease. Vol. 110, Circulation Research. Circ Res; 2012. p. 1097-108.

3. Quarles EK, Dai DF, Tocchi A, Basisty N, Gitari L, Rabinovitch PS. Quality control systems in cardiac aging. Ageing Res Rev [Internet]. 2015;23(PA):101-15. Available from:

http://dx.doi.org/10.1016/j.arr.2015.02.003

4. Stanley WC, Recchia FA, Lopaschuk GD. Myocardial substrate metabolism in the normal and failing heart. Vol. 85, Physiological Reviews. 2005. p. 1093-129.

5. Dai DF, Chen T, Johnson SC, Szeto H, Rabinovitch PS. Cardiac aging: From molecular mechanisms to significance in human health and disease [Internet]. Vol. 16, Antioxidants and Redox Signaling. Mary Ann Liebert, Inc.; 2012 [cited 2020 Aug 26]. p. 1492-536. Available from:

/pmc/articles/PMC3329953/?report=abstract

6. Melzer D, Hurst AJ, Frayling T. Genetic Variation and Human Aging: Progress and Prospects. Journals Gerontol Ser A Biol Sci Med Sci [Internet]. 2007 Mar 1 [cited 2019 Mar 22];62(3):301-7. Available from: https://academic.oup.com/biomedgerontology/articlelookup/doi/10.1093/gerona/62.3.301

7. López-Otín C, Blasco MA, Partridge L, Serrano M, Kroemer G. The hallmarks of aging. Vol. 153, Cell. Cell Press; 2013. p. 1194.

8. Singh PP, Demmitt BA, Nath RD, Brunet A. The Genetics of Aging: A Vertebrate Perspective [Internet]. Vol. 177, Cell. Cell Press; 2019 [cited 2020 Mar 17]. p. 200-20. Available from: https://linkinghub.elsevier.com/retrieve/pii/S0092867419302211

9. Bahar R, Hartmann CH, Rodriguez KA, Denny AD, Busuttil RA, Dollé MET, et al. Increased cell-tocell variation in gene expression in ageing mouse heart. Nature [Internet]. 2006 Jun 22 [cited 2020 Aug 7];441(7096):1011-4. Available from: https://www.nature.com/articles/nature04844

10. Işıldak U, Somel M, Thornton JM, Dönertaş HM. Temporal changes in the gene expression heterogeneity during brain development and aging. Sci Rep [Internet]. 2020 Dec 1 [cited 2020 Aug 7];10(1):1-15. Available from: https://www.nature.com/articles/s41598-020-60998-0 
11. Gonskikh Y, Polacek N. Alterations of the translation apparatus during aging and stress response. Mech Ageing Dev [Internet]. 2017 [cited 2020 Aug 7];1-0. Available from:

www.elsevier.com/locate/mechagedev

12. Takemon Y, Chick JM, Gerdes Gyuricza I, Skelly DA, Devuyst O, Gygi SP, et al. Proteomic and transcriptomic profiling reveal different aspects of aging in the kidney. Elife [Internet]. 2021 Mar 9 [cited 2021 Mar 10];10. Available from: https://elifesciences.org/articles/62585

13. Waldera-Lupa DM, Kalfalah F, Florea AM, Sass S, Kruse F, Rieder V, et al. Proteome-wide analysis reveals an age-associated cellular phenotype of in situ aged human fibroblasts. Aging (Albany NY) [Internet]. 2014 [cited 2020 Aug 7];6(10):856-78. Available from:

/pmc/articles/PMC4247387/?report=abstract

14. Wei Y-N, Hu H-Y, Xie G-C, Fu N, Ning Z-B, Zeng R, et al. Transcript and protein expression decoupling reveals RNA binding proteins and miRNAs as potential modulators of human aging. Genome Biol [Internet]. 2015 Dec 22 [cited 2020 Dec 21];16(1):41. Available from: https://genomebiology.biomedcentral.com/articles/10.1186/s13059-015-0608-2

15. Lakatta EG, Levy D. Arterial and Cardiac Aging: Major Shareholders in Cardiovascular Disease Enterprises. Circulation [Internet]. 2003 Jan 7 [cited 2019 Jun 7];107(1):139-46. Available from: https://www.ahajournals.org/doi/10.1161/01.CIR.0000048892.83521.58

16. Kiper C, Grimes B, Van Zant G, Satin J. Mouse Strain Determines Cardiac Growth Potential. Singh SR, editor. PLoS One [Internet]. 2013 Aug 5 [cited 2021 Jan 15];8(8):e70512. Available from: https://dx.plos.org/10.1371/journal.pone.0070512

17. Barrick CJ, Rojas M, Schoonhoven R, Smyth SS, Threadgill DW. Cardiac response to pressure overload in 129S1/SvImJ and C57BL/6J mice: Temporal- and background-dependent development of concentric left ventricular hypertrophy. Am J Physiol - Hear Circ Physiol [Internet]. 2007 May [cited 2021 Jan 15];292(5). Available from: https://pubmed.ncbi.nlm.nih.gov/17172276/

18. Forte E, Skelly DA, Chen M, Daigle S, Morelli KA, Hon O, et al. Dynamic Interstitial Cell Response during Myocardial Infarction Predicts Resilience to Rupture in Genetically Diverse Mice. Cell Rep [Internet]. 2020;30(9):3149-3163.e6. Available from:

https://doi.org/10.1016/j.celrep.2020.02.008 
19. Xing S, Tsaih SW, Yuan R, Svenson KL, Jorgenson LM, So M, et al. Genetic influence on electrocardiogram time intervals and heart rate in aging mice. Am J Physiol - Hear Circ Physiol [Internet]. 2009 Jun [cited 2021 Jan 15];296(6):H1907-13. Available from: https://www.physiology.org/doi/10.1152/ajpheart.00681.2008

20. Avila JJ, Kim SK, Massett MP. Differences in Exercise Capacity and Responses to Training in 24 Inbred Mouse Strains. Front Physiol [Internet]. 2017 Nov 30 [cited 2021 Jan 15];8(NOV):974. Available from: http://journal.frontiersin.org/article/10.3389/fphys.2017.00974/full

21. Shorter JR, Huang W, Beak JY, Hua K, Gatti DM, de Villena FPM, et al. Quantitative trait mapping in Diversity Outbred mice identifies two genomic regions associated with heart size. Mamm Genome [Internet]. 2018 Feb 1 [cited 2021 Jan 15];29(1-2):80-9. Available from: /pmc/articles/PMC6340297/?report=abstract

22. Salimova E, Nowak KJ, Estrada AC, Furtado MB, McNamara E, Nguyen Q, et al. Variable outcomes of human heart attack recapitulated in genetically diverse mice. npj Regen Med [Internet]. 2019 Dec 1 [cited 2021 Jan 15];4(1):1-15. Available from: https://doi.org/10.1038/s41536-019-0067-6

23. Svenson KL, Gatti DM, Valdar W, Welsh CE, Cheng R, Chesler EJ, et al. High-resolution genetic mapping using the mouse Diversity Outbred population. Genetics [Internet]. 2012 [cited 2020 Aug 26];190(2):437-47. Available from: /pmc/articles/PMC3276626/?report=abstract

24. Saul MC, Philip VM, Reinholdt LG, Chesler EJ. High-Diversity Mouse Populations for Complex Traits. Vol. 35, Trends in Genetics. Elsevier Ltd; 2019. p. 501-14.

25. Cellerino A, Ori A. What have we learned on aging from omics studies? [Internet]. Vol. 70, Seminars in Cell and Developmental Biology. Elsevier Ltd; 2017 [cited 2020 Aug 23]. p. 177-89. Available from: https://pubmed.ncbi.nlm.nih.gov/28630026/

26. Yu G, Wang L-G, Han Y, He Q-Y. clusterProfiler: an R package for comparing biological themes among gene clusters. OMICS [Internet]. 2012 May [cited 2019 Mar 29];16(5):284-7. Available from: http://www.ncbi.nlm.nih.gov/pubmed/22455463

27. Subramanian A, Tamayo P, Mootha VK, Mukherjee S, Ebert BL, Gillette MA, et al. Gene set enrichment analysis: A knowledge-based approach for interpreting genome-wide expression profiles. Proc Natl Acad Sci U S A [Internet]. 2005 Oct 25 [cited 2020 Aug 23];102(43):15545-50. Available from: www.pnas.orgcgidoi10.1073pnas.0506580102 
28. Love MI, Huber W, Anders S. Moderated estimation of fold change and dispersion for RNA-seq data with DESeq2. Genome Biol [Internet]. 2014;15(12):550. Available from: http://genomebiology.biomedcentral.com/articles/10.1186/s13059-014-0550-8

29. Toba H, de Castro Brás LE, Baicu CF, Zile MR, Lindsey ML, Bradshaw AD. Increased ADAMTS1 mediates SPARC-dependent collagen deposition in the aging myocardium. Am J Physiol Endocrinol Metab [Internet]. 2016 [cited 2019 Mar 29];310(11):E1027-35. Available from: http://www.ncbi.nlm.nih.gov/pubmed/27143554

30. Khan SS, Shah SJ, Strande JL, Baldridge AS, Klyachko E, Flevaris P, et al. Identification of a Novel Familial Fibrotic Cardiomyopathy with a Loss-of-Function Mutation in SERPINE1. J Card Fail [Internet]. 2017 Aug 1 [cited 2019 Mar 29];23(8):S3. Available from: https://linkinghub.elsevier.com/retrieve/pii/S1071916417302233

31. Münch J, Grivas D, González-Rajal Á, Torregrosa-Carrión R, de la Pompa JL. Notch signalling restricts inflammation and serpine1 expression in the dynamic endocardium of the regenerating zebrafish heart. Development [Internet]. 2017 Apr 15 [cited 2019 Mar 29];144(8):1425-40. Available from: http://www.ncbi.nlm.nih.gov/pubmed/28242613

32. Heath E, Tahri D, Andermarcher E, Schofield P, Fleming S, Boulter CA. Abnormal skeletal and cardiac development, cardiomyopathy, muscle atrophy and cataracts in mice with a targeted disruption of the Nov (Ccn3) gene. BMC Dev Biol [Internet]. 2008 Feb 20 [cited 2019 Mar 29];8(1):18. Available from: http://www.ncbi.nlm.nih.gov/pubmed/18289368

33. Li CL, Martinez V, He B, Lombet A, Perbal B. A role for CCN3 (NOV) in calcium signalling. Mol Pathol [Internet]. 2002 Aug [cited 2019 Mar 29];55(4):250-61. Available from: http://www.ncbi.nlm.nih.gov/pubmed/12147716

34. Gordon JW. Regulation of cardiac myocyte cell death and differentiation by myocardin. Mol Cell Biochem [Internet]. 2018 Jan 19 [cited 2019 Mar 29];437(1-2):119-31. Available from: http://www.ncbi.nlm.nih.gov/pubmed/28631251

35. Barger PM, Kelly DP. PPAR signaling in the control of cardiac energy metabolism. Vol. 10, Trends in Cardiovascular Medicine. 2000. p. 238-45.

36. Erol A. The functions of PPARs in aging and longevity [Internet]. Vol. 2007, PPAR Research. Hindawi Limited; 2007 [cited 2020 Aug 12]. Available from: 
/pmc/articles/PMC2254525/?report=abstract

37. Chu G, Kranias EG. Phospholamban as a therapeutic modality in heart failure. Novartis Found Symp [Internet]. 2006 [cited 2019 Mar 29];274:156-71; discussion 172-5, 272-6. Available from: http://www.ncbi.nlm.nih.gov/pubmed/17019811

38. Hu Z, Liu F, Li M, He J, Huang J, Rao DC, et al. Associations of Variants in the CACNA1A and CACNA1C Genes With Longitudinal Blood Pressure Changes and Hypertension Incidence: The GenSalt Study. Am J Hypertens [Internet]. 2016 [cited 2019 Mar 29];29(11):1301-6. Available from: http://www.ncbi.nlm.nih.gov/pubmed/27418245

39. Lu B, Tigchelaar W, Ruifrok WPT, van Gilst WH, de Boer RA, Silljé HHW. DHRS7c, a novel cardiomyocyte-expressed gene that is down-regulated by adrenergic stimulation and in heart failure. Eur J Heart Fail [Internet]. 2012 Jan 1 [cited 2019 Mar 29];14(1):5-13. Available from: http://doi.wiley.com/10.1093/eurjhf/hfr152

40. Chen J, Sadowski HB, Kohanski RA, Wang L-H. Stat5 is a physiological substrate of the insulin receptor. Proc Natl Acad Sci U S A [Internet]. 1997 [cited 2019 Mar 29];94(6):2295. Available from: https://www.ncbi.nlm.nih.gov/pmc/articles/PMC20081/

41. Storz P, Döppler H, Pfizenmaier K, Müller G. Insulin selectively activates STAT5b, but not STAT5a, via a JAK2-independent signalling pathway in Kym-1 rhabdomyosarcoma cells. FEBS Lett [Internet]. 1999 Dec 31 [cited 2019 Mar 29];464(3):159-63. Available from: https://www.sciencedirect.com/science/article/pii/S0014579399016890

42. Grigorov I, Lazić T, Cvetković I, Milosavljević T, Petrović M. Opposite nuclear level and binding activity of STAT5B and STAT3 proteins with rat haptoglobin gene under normal and turpentine induced acute phase conditions. Mol Biol Rep. 2001 Dec 1;28(4):217-22.

43. Kang MJ, Yang S, Baek JW, Shim YS, Oh YJ, Hwang IT. Fetuin-A as an Alternative Marker for Insulin Resistance and Cardiovascular Risk in Prepubertal Children. J Atheroscler Thromb. 2017;

44. Westenfeld R, Schäfer C, Krüger T, Haarmann C, Schurgers $L$, Reutelingsperger $C$, et al. Fetuin-A protects against atherosclerotic calcification in CKD. J Am Soc Nephrol [Internet]. 2009 Jun [cited 2020 Aug 12];20(6):1264-74. Available from: /pmc/articles/PMC2689898/?report=abstract

45. Lindman BR, Clavel M-A, Mathieu $\mathrm{P}$, lung $\mathrm{B}$, Lancellotti $\mathrm{P}$, Otto $\mathrm{CM}$, et al. Calcific aortic stenosis. 
Nat Rev Dis Prim [Internet]. 2016 [cited 2019 Mar 29];2:16006. Available from:

http://www.ncbi.nlm.nih.gov/pubmed/27188578

46. Schaum N, Lehallier B, Hahn O, Pálovics R, Hosseinzadeh S, Lee SE, et al. Ageing hallmarks exhibit organ-specific temporal signatures. Nature [Internet]. 2020 [cited 2021 Jan 20];583(7817):596.

Available from: /pmc/articles/PMC7757734/?report=abstract

47. Yu Q, Xiao H, Jedrychowski MP, Schweppe DK, Navarrete-Perea J, Knott J, et al. Sample multiplexing for targeted pathway proteomics in aging mice. Proc Natl Acad Sci U S A [Internet]. 2020 May 5 [cited 2021 Jan 28];117(18):9723-32. Available from: www.pnas.org/cgi/doi/10.1073/pnas.1919410117

48. Muslin AJ. Akt2: A critical regulator of cardiomyocyte survival and metabolism. In: Pediatric Cardiology. 2011. p. 317-22.

49. Pillai VB, Sundaresan NR, Gupta MP. Regulation of Akt signaling by sirtuins: its implication in cardiac hypertrophy and aging. Circ Res [Internet]. 2014 Jan 17 [cited 2020 Aug 12];114(2):36878. Available from: http://www.ncbi.nlm.nih.gov/pubmed/24436432

50. DeBosch B, Treskov I, Lupu TS, Weinheimer C, Kovacs A, Courtois M, et al. Akt1 is required for physiological cardiac growth. Circulation. 2006 May;113(17):2097-104.

51. DeBosch B, Sambandam N, Weinheimer C, Courtois M, Muslin AJ. Akt2 regulates cardiac metabolism and cardiomyocyte survival. J Biol Chem. 2006 Oct 27;281(43):32841-51.

52. Essop MF, Camp HS, Cheol SC, Sharma S, Fryer RM, Reinhart GA, et al. Reduced heart size and increased myocardial fuel substrate oxidation in ACC2 mutant mice. Am J Physiol - Hear Circ Physiol. 2008 Jul;295(1).

53. Kaslow HR, Lesikar DD. Isozymes of glycogen synthase. FEBS Lett. 1984 Jul 9;172(2):294-8.

54. Wu G, Yussman MG, Barrett TJ, Hahn HS, Osinska H, Hilliard GM, et al. Increased Myocardial Rab GTPase Expression A Consequence and Cause of Cardiomyopathy. 2001 [cited 2020 Jan 30]; Available from: http://www.circresaha.org

55. Martinez O, Goud B. Rab proteins. Biochim Biophys Acta - Mol Cell Res. 1998 Aug 14;1404(12):101-12.

56. Yamano K, Wang C, Sarraf SA, Münch C, Kikuchi R, Noda NN, et al. Endosomal rab cycles regulate 
parkin-mediated mitophagy. Elife. 2018 Jan 23;7.

57. Touchot N, Zahraoui A, Vielh E, Tavitian A. Biochemical properties of the YPT-related rab1B protein. Comparison with rab1A. FEBS Lett. 1989 Oct 9;256(1-2):79-84.

58. Vincent B, De Bock K, Ramaekers M, Van Den Eede E, Van Leemputte M, Hespel P, et al. ACTN3 (R577X) genotype is associated with fiber type distribution. Physiol Genomics. 2007 Dec 19;32(1):58-63.

59. MacArthur DG, Seto JT, Raftery JM, Quinlan KG, Huttley GA, Hook JW, et al. Loss of ACTN3 gene function alters mouse muscle metabolism and shows evidence of positive selection in humans. Nat Genet. 2007 Oct;39(10):1261-5.

60. Anisimova AS, Alexandrov Al, Makarova NE, Gladyshev VN, Dmitriev SE. Protein synthesis and quality control in aging. Vol. 10, Aging. Impact Journals LLC; 2018. p. 4269-88.

61. Taggart JC, Zauber H, Selbach M, Li GW, McShane E. Keeping the Proportions of Protein Complex Components in Check. Vol. 10, Cell Systems. Cell Press; 2020. p. 125-32.

62. Kelmer Sacramento E, Kirkpatrick JM, Mazzetto M, Baumgart M, Bartolome A, Di Sanzo S, et al. Reduced proteasome activity in the aging brain results in ribosome stoichiometry loss and aggregation. Mol Syst Biol [Internet]. 2020 Jun 18 [cited 2021 Jan 28];16(6):e9596. Available from: https://onlinelibrary.wiley.com/doi/10.15252/msb.20209596

63. Ori A, Toyama BH, Harris MS, Bock T, Iskar M, Bork P, et al. Integrated Transcriptome and Proteome Analyses Reveal Organ-Specific Proteome Deterioration in Old Rats. Cell Syst [Internet]. 2015 Sep 23 [cited 2020 Dec 21];1(3):224-37. Available from: https://pubmed.ncbi.nlm.nih.gov/27135913/

64. Giurgiu M, Reinhard J, Brauner B, Dunger-Kaltenbach I, Fobo G, Frishman G, et al. CORUM: the comprehensive resource of mammalian protein complexes-2019. Nucleic Acids Res [Internet]. 2019 [cited 2020 Apr 28];47:559-63. Available from: http://mips.helmholtzmuenchen.de/corum/.

65. McKenzie AT, Katsyv I, Song WM, Wang M, Zhang B. DGCA: A comprehensive R package for Differential Gene Correlation Analysis. BMC Syst Biol. 2016 Nov 15;10(1):1-25.

66. Tanaka K. The proteasome: Overview of structure and functions [Internet]. Vol. 85, Proceedings 
of the Japan Academy Series B: Physical and Biological Sciences. The Japan Academy; 2009 [cited 2021 Jan 7]. p. 12-36. Available from:/pmc/articles/PMC3524306/?report=abstract

67. Yao C, Chen G, Song C, Keefe J, Mendelson M, Huan T, et al. Genome-wide mapping of plasma protein QTLs identifies putatively causal genes and pathways for cardiovascular disease. Nat Commun [Internet]. 2018 Dec 1 [cited 2020 Aug 23];9(1):1-11. Available from: www.nature.com/naturecommunications

68. Hause RJ, Stark AL, Antao NN, Gorsic LK, Chung SH, Brown CD, et al. Identification and validation of genetic variants that influence transcription factor and cell signaling protein levels. Am J Hum Genet [Internet]. 2014 Aug 7 [cited 2020 Aug 23];95(2):194-208. Available from: http://dx.doi.org/10.1016/j.ajhg.2014.07.005.

69. Chick JM, Munger SC, Simecek P, Huttlin EL, Choi K, Daniel M. Defining the consequences of genetic variation on a proteome-wide scale. Nature [Internet]. 2016;002801:1-39. Available from: http://dx.doi.org/10.1038/nature18270

70. Albert FW, Bloom JS, Siegel J, Day L, Kruglyak L. Genetics of trans-regulatory variation in gene expression. Elife [Internet]. $2018 \mathrm{Jul} 17$ [cited $2020 \mathrm{Jul}$ 17];7. Available from: /pmc/articles/PMC6072440/?report=abstract

71. Battle A, Khan Z, Wang SH, Mitrano A, Ford MJ, Pritchard JK, et al. Impact of regulatory variation from RNA to protein. Science (80- ) [Internet]. 2015 Feb 6 [cited 2020 Aug 23];347(6222):664-7. Available from: https://pubmed.ncbi.nIm.nih.gov/25657249/

72. Gao J, Schatton D, Martinelli P, Hansen H, Pla-Martin D, Barth E, et al. CLUH regulates mitochondrial biogenesis by binding mRNAs of nuclear-encoded mitochondrial proteins. J Cell Biol. 2014;207(2):213-23.

73. Schatton D, Pla-Martin D, Marx MC, Hansen H, Mourier A, Nemazanyy I, et al. CLUH regulates mitochondrial metabolism by controlling translation and decay of target mRNAs. J Cell Biol. 2017 Mar 6;216(3):675-93.

74. Billia F, Hauck L, Grothe D, Konecny F, Rao V, Kim RH, et al. Parkinson-susceptibility gene DJ1/PARK7 protects the murine heart from oxidative damage in vivo. Proc Natl Acad Sci U S A [Internet]. 2013 Apr 9 [cited 2020 Jun 30];110(15):6085-90. Available from: https://pubmed.ncbi.nlm.nih.gov/23530187/ 
75. Sarikhani M, Maity S, Mishra S, Jain A, Tamta AK, Ravi V, et al. SIRT2 deacetylase represses NFAT transcription factor to maintain cardiac homeostasis. J Biol Chem. 2018 Apr 6;293(14):5281-94.

76. Tang X, Chen XF, Wang NY, Wang XM, Liang ST, Zheng W, et al. SIRT2 acts as a cardioprotective deacetylase in pathological cardiac hypertrophy. Circulation [Internet]. 2017 Nov 1 [cited 2020 Jun 30];136(21):2051-67. Available from: /pmc/articles/PMC5698109/?report=abstract

77. Takahashi Y, Coppola D, Matsushita N, Cualing HD, Sun M, Sato Y, et al. Bif-1 interacts with Beclin 1 through UVRAG and regulates autophagy and tumorigenesis. Nat Cell Biol [Internet]. 2007 Oct [cited 2020 Jun 29];9(10):1142-51. Available from: https://pubmed.ncbi.nlm.nih.gov/17891140/

78. Takahashi Y, Meyerkord CL, Wang HG. Bif-1/Endophilin B1: A candidate for crescent driving force in autophagy [Internet]. Vol. 16, Cell Death and Differentiation. NIH Public Access; 2009 [cited 2020 Jun 29]. p. 947-55. Available from: /pmc/articles/PMC2697278/?report=abstract

79. Escobar KA, Cole NH, Mermier CM, VanDusseldorp TA. Autophagy and aging: Maintaining the proteome through exercise and caloric restriction [Internet]. Vol. 18, Aging Cell. Blackwell Publishing Ltd; 2019 [cited 2020 Jun 29]. Available from: https://onlinelibrary.wiley.com/doi/full/10.1111/acel.12876

80. Wei YN, Hu HY, Xie GC, Fu N, Ning Z Bin, Zeng R, et al. Transcript and protein expression decoupling reveals RNA binding proteins and miRNAs as potential modulators of human aging. Genome Biol. 2015 Feb 22;16(1).

81. Strait JB, Lakatta EG. Aging-Associated Cardiovascular Changes and Their Relationship to Heart Failure. Vol. 8, Heart Failure Clinics. NIH Public Access; 2012. p. 143-64.

82. Biernacka A, Frangogiannis NG. Aging and Cardiac Fibrosis. Vol. 2, Aging and Disease •. 2011.

83. Horn MA, Graham HK, Richards MA, Clarke JD, Greensmith DJ, Briston SJ, et al. Age-related divergent remodeling of the cardiac extracellular matrix in heart failure: Collagen accumulation in the young and loss in the aged. J Mol Cell Cardiol. 2012 Jul;53(1):82-90.

84. Sessions AO, Engler AJ. Mechanical Regulation of Cardiac Aging in Model Systems. Vol. 118, Circulation Research. Lippincott Williams and Wilkins; 2016. p. 1553-62.

85. Nishtala K, Phong TQ, Steil L, Sauter M, Salazar MG, Kandolf R, et al. Proteomic analyses of age related changes in A.BY/SnJ mouse hearts. Proteome Sci. 2013;11(1). 
86. Chakravarti B, Oseguera M, Dalal N, Fathy P, Mallik B, Raval A, et al. Proteomic profiling of aging in the mouse heart: Altered expression of mitochondrial proteins. Arch Biochem Biophys [Internet]. 2008 Jun 1 [cited 2020 Aug 12];474(1):22-31. Available from: https://linkinghub.elsevier.com/retrieve/pii/S0003986108000556

87. Mills MA, Yang N, Weinberger RP, Woude DL Vander, Beggs AH, Easteal S, et al. Differential expression of the actin-binding proteins, $\alpha$-actinin- 2 and-3, in different species: implications for the evolution of functional redundancy [Internet]. Vol. 10, Human Molecular Genetics. 2001 [cited 2020 Mar 5]. Available from: http://www.ncbi.nlm.nih.gov/

88. Arvanitis M, Tampakakis E, Zhang Y, Wang W, Auton A, Dutta D, et al. Genome-wide association and multi-omic analyses reveal ACTN2 as a gene linked to heart failure. Nat Commun [Internet]. 2020 Dec 28 [cited 2020 Mar 5];11(1):1122. Available from: http://www.nature.com/articles/s41467-020-14843-7

89. Rajabi M, Kassiotis C, Razeghi P, Taegtmeyer $\mathrm{H}$. Return to the fetal gene program protects the stressed heart: A strong hypothesis. Heart Fail Rev [Internet]. 2007 Dec 19 [cited 2020 Feb 28];12(3-4):331-43. Available from: http://link.springer.com/10.1007/s10741-007-9034-1

90. Taegtmeyer $\mathrm{H}$, Sen S, Vela D. Return to the fetal gene program: A suggested metabolic link to gene expression in the heart. In: Annals of the New York Academy of Sciences [Internet]. Blackwell Publishing Inc.; 2010 [cited 2020 Jun 30]. p. 191-8. Available from: /pmc/articles/PMC3625436/?report=abstract

91. Korvald C, Elvenes OP, Myrmel T. Myocardial substrate metabolism influences left ventricular energetics in vivo. Am J Physiol - Hear Circ Physiol. 2000;278(4 47-4).

92. Yeo EJ. Hypoxia and aging. Vol. 51, Experimental and Molecular Medicine. Nature Publishing Group; 2019. p. 1-15.

93. Moreno Rosa C, Priscilla Xavier N, Henrique Campos D, Angélica Henrique Fernandes A, Diarcadia Mariano Cezar M, Felippe Martinez P, et al. Diabetes mellitus activates fetal gene program and intensifies cardiac remodeling and oxidative stress in aged spontaneously hypertensive rats [Internet]. Vol. 12, Cardiovascular Diabetology. 2013 [cited 2020 Feb 28]. Available from: http://www.cardiab.com/content/12/1/152

94. Connelly KA, Kelly DJ, Zhang Y, Prior DL, Advani A, Cox AJ, et al. Inhibition of protein kinase C- $\beta$ by 
ruboxistaurin preserves cardiac function and reduces extracellular matrix production in diabetic cardiomyopathy. Circ Hear Fail [Internet]. 2009 Mar [cited 2020 Feb 28];2(2):129-37. Available from: http://www.ncbi.nlm.nih.gov/pubmed/19808328

95. Harper JW, Bennett EJ. Proteome complexity and the forces that drive proteome imbalance. Vol. 537, Nature. Nature Publishing Group; 2016. p. 328-38.

96. Carrard G, Bulteau AL, Petropoulos I, Friguet B. Impairment of proteasome structure and function in aging. Vol. 34, International Journal of Biochemistry and Cell Biology. Pergamon; 2002. p. 1461-74.

97. Bulteau AL, Szweda LI, Friguet B. Age-dependent declines in proteasome activity in the heart. Arch Biochem Biophys [Internet]. 2002 Jan 15 [cited 2021 Jan 7];397(2):298-304. Available from: https://linkinghub.elsevier.com/retrieve/pii/S0003986101926633

98. Predmore JM, Wang P, Davis F, Bartolone S, Westfall M V, Dyke DB, et al. Ubiquitin Proteasome Dysfunction in Human Hypertrophic and Dilated Cardiomyopathies. Circulation. 2010;121(8):997-1004.

99. Bulteau AL, Szweda LI, Friguet B. Age-dependent declines in proteasome activity in the heart. Arch Biochem Biophys [Internet]. 2002 Jan 15 [cited 2021 Jan 8];397(2):298-304. Available from: https://linkinghub.elsevier.com/retrieve/pii/S0003986101926633

100. Higuchi-Sanabria R, Frankino PA, Paul JW, Tronnes SU, Dillin A. A Futile Battle? Protein Quality Control and the Stress of Aging [Internet]. Vol. 44, Developmental Cell. Cell Press; 2018 [cited 2020 Jun 30]. p. 139-63. Available from: https://pubmed.ncbi.nlm.nih.gov/29401418/

101. Belmont PJ, Tadimalla A, Chen WJ, Martindale JJ, Thuerauf DJ, Marcinko M, et al. Coordination of Growth and Endoplasmic Reticulum Stress Signaling by Regulator of Calcineurin 1 (RCAN1), a Novel ATF6-inducible Gene * $\square$ S. 2008 [cited 2019 Dec 19]; Available from: http://www.jbc.org

102. Szegezdi E, Logue SE, Gorman AM, Samali A. Mediators of endoplasmic reticulum stress-induced apoptosis. Vol. 7, EMBO Reports. European Molecular Biology Organization; 2006. p. 880-5.

103. Martindale JJ, Fernandez R, Thuerauf D, Whittaker R, Gude N, Sussman MA, et al. Endoplasmic reticulum stress gene induction and protection from ischemia/reperfusion injury in the hearts of transgenic mice with a tamoxifen-regulated form of ATF6. Circ Res. 2006 May;98(9):1186-93. 
104. Toko H, Takahashi H, Kayama Y, Okada S, Minamino T, Terasaki F, et al. ATF6 is important under both pathological and physiological states in the heart. J Mol Cell Cardiol. 2010 Jul;49(1):113-20.

105. Ishimi Y, Kojima M, Takeuchi F, Miyamoto T, Yamada MA, Hanaoka F. Changes in chromatin structure during aging of human skin fibroblasts. Exp Cell Res. 1987;169(2):458-67.

106. Smeal T, Claus J, Kennedy B, Cole F, Guarente L. Loss of transcriptional silencing causes sterility in old mother cells of S. cerevisiae. Cell. 1996 Feb 23;84(4):633-42.

107. Enright HU, Miller WJ, Hebbel RP. Nucleosomal histone protein protects DNA from iron-mediated damage. Vol. 20, Nucleic Acids Research.

108. Ljungman M, Hanawalt PC. Efficient protection against oxidative DNA damage in chromatin. Mol Carcinog. 1992;5(4):264-9.

109. Cuddeback SM, Yamaguchi H, Komatsu K, Miyashita T, Yamada M, Wu C, et al. Molecular cloning and characterization of Bif-1. A novel Src homology 3 domain-containing protein that associates with Bax. J Biol Chem [Internet]. 2001 Jun 8 [cited 2020 Jun 29];276(23):20559-65. Available from: https://pubmed.ncbi.nlm.nih.gov/11259440/

110. Karbowski M, Jeong SY, Youle RJ. Endophilin B1 is required for the maintenance of mitochondrial morphology. J Cell Biol. 2004 Sep 27;166(7):1027-39.

111. Komatsu M, Waguri S, Chiba T, Murata S, Iwata JI, Tanida I, et al. Loss of autophagy in the central nervous system causes neurodegeneration in mice. Nature. 2006 Jun 15;441(7095):880-4.

112. Nakai A, Yamaguchi O, Takeda T, Higuchi Y, Hikoso S, Taniike M, et al. The role of autophagy in cardiomyocytes in the basal state and in response to hemodynamic stress. Nat Med. 2007 May;13(5):619-24.

113. Takahashi Y, Hori T, Cooper TK, Liao J, Desai N, Serfass JM, et al. Bif-1 haploinsufficiency promotes chromosomal instability and accelerates Myc-driven lymphomagenesis via suppression of mitophagy. Blood [Internet]. 2013 Feb 28 [cited 2020 Jun 29];121(9):1622-32. Available from: /pmc/articles/PMC3587325/?report=abstract

114. Taneike M, Yamaguchi O, Nakai A, Hikoso S, Takeda T, Mizote I, et al. Inhibition of autophagy in the heart induces age-related cardiomyopathy. Autophagy [Internet]. 2010 [cited 2020 Jun 29];6(5):600-6. Available from: 
https://www.tandfonline.com/action/journallnformation?journalCode=kaup20

115. Wilson Van Voorhis CR, Morgan BL. Understanding Power and Rules of Thumb for Determining Sample Sizes. Tutor Quant Methods Psychol [Internet]. 2007 Sep 1 [cited 2020 Sep 14];3(2):4350. Available from: https://scinapse.io/papers/112288907

116. Holm S. A Simple Sequentially Rejective Multiple Test Procedure A Simple Sequentially Rejective Multiple Test Procedure. Scand J Stat. 1979;6(2):65-70.

117. Gatti DM, Svenson KL, Shabalin A, Wu LY, Valdar WW, Simecek P, et al. Quantitative trait locus mapping methods for diversity outbred mice. G3 Genes, Genomes, Genet [Internet]. 2014 [cited 2020 Sep 14];4(9):1623-33. Available from: /pmc/articles/PMC4169154/?report=abstract

118. Raghupathy N, Choi K, Vincent MJ, Beane GL, Sheppard KS, Munger SC, et al. Hierarchical analysis of RNA-seq reads improves the accuracy of allele-specific expression. Valencia A, editor. Bioinformatics [Internet]. 2018 Jul 1 [cited 2019 Jul 29];34(13):2177-84. Available from: https://academic.oup.com/bioinformatics/article/34/13/2177/4850941

119. Conover WJ, Iman RL. Rank Transformations as a Bridge Between Parametric and Nonparametric Statistics. Am Stat [Internet]. 1981 Aug [cited 2020 Jul 17];35(3):124. Available from: https://www.jstor.org/stable/2683975

120. Eng JK, McCormack AL, Yates JR. An approach to correlate tandem mass spectral data of peptides with amino acid sequences in a protein database. J Am Soc Mass Spectrom. 1994 Nov 1;5(11):976-89.

121. Huttlin EL, Jedrychowski MP, Elias JE, Goswami T, Rad R, Beausoleil SA, et al. A tissue-specific atlas of mouse protein phosphorylation and expression. Cell [Internet]. 2010 Dec 23 [cited 2020 Jul 10];143(7):1174-89. Available from: /pmc/articles/PMC3035969/?report=abstract

122. Bates D, Mächler M, Bolker B, Walker S. Fitting Linear Mixed-Effects Models Using Ime4. J Stat Softw. 2015;67(1).

123. Yang J, Zaitlen NA, Goddard ME, Visscher PM, Price AL. Advantages and pitfalls in the application of mixed-model association methods [Internet]. Vol. 46, Nature Genetics. Nature Publishing Group; 2014 [cited 2020 Aug 23]. p. 100-6. Available from:

https://pubmed.ncbi.nlm.nih.gov/24473328/ 
124. Churchill GA, Doerge RW. Empirical threshold values for quantitative trait mapping. Genetics. 1994;138(3):963-71.

125. Broman KW, Gatti DM, Simecek P, Furlotte NA, Prins P, Sen Ś, et al. R/qt/2: Software for Mapping Quantitative Trait Loci with High-Dimensional Data and Multiparent Populations. Genetics [Internet]. 2019 Feb 1 [cited 2019 Mar 29];211(2):495-502. Available from: http://www.ncbi.nlm.nih.gov/pubmed/30591514

126. Shi N, Li C-X, Cui X-B, Tomarev SI, Chen S-Y. Olfactomedin 2 Regulates Smooth Muscle Phenotypic Modulation and Vascular Remodeling Through Mediating Runx2 Binding to SRF Correspondence to. Arter Thromb Vasc Biol [Internet]. 2017 [cited 2019 Mar 29];37(3):446-54. Available from: http://www.gtexportal.org/home/gene/

127. Vassort G, Talavera K, Alvarez JL. Role of T-type Ca2+ channels in the heart. Cell Calcium. 2006;40(2):205-20.

128. Ferron L, Capuano V, Ruchon Y, Deroubaix E, Coulombe A, Renaud J-F. Angiotensin II Signaling Pathways Mediate Expression of Cardiac T-Type Calcium Channels. 2003 [cited 2020 Jan 27]; Available from: http://www.circresaha.org

129. Berkholz J, Zakrzewicz A, Munz B. skNAC depletion stimulates myoblast migration and perturbs sarcomerogenesis by enhancing calpain 1 and 3 activity. Biochem J [Internet]. 2013 Jul 15 [cited 2019 Mar 29];453(2):303-10. Available from: http://www.ncbi.nlm.nih.gov/pubmed/23662692

130. Munz B, Wiedmann M, Lochmüller H, Werner S. Cloning of novel injury-regulated genes. Implications for an important role of the muscle-specific protein skNAC in muscle repair. J Biol Chem [Internet]. 1999 May 7 [cited 2019 Mar 29];274(19):13305-10. Available from: http://www.ncbi.nlm.nih.gov/pubmed/10224091

131. Yotov W V, St-Arnaud R. Differential splicing-in of a proline-rich exon converts alphaNAC into a muscle-specific transcription factor. Genes Dev [Internet]. 1996 Jul 15 [cited 2019 Mar 29];10(14):1763-72. Available from: http://www.ncbi.nlm.nih.gov/pubmed/8698236

132. Howroyd P, Swanson C, Dunn C, Cattley RC, Corton JC. Decreased Longevity and Enhancement of Age-Dependent Lesions in Mice Lacking the Nuclear Receptor Peroxisome Proliferator-Activated Receptor $\alpha$ (PPAR $\alpha$ ). Toxicol Pathol [Internet]. 2004 Aug 2 [cited 2019 Mar 29];32(5):591-9. Available from: http://www.ncbi.nlm.nih.gov/pubmed/15603543 
133. Yuan J, Mo H, Luo J, Zhao S, Liang S, Jiang Y, et al. PPAR $\alpha$ activation alleviates damage to the cytoskeleton during acute myocardial ischemia/reperfusion in rats. Mol Med Rep [Internet]. 2018 Mar 16 [cited 2019 Mar 29];17(5):7218-26. Available from:

http://www.ncbi.nlm.nih.gov/pubmed/29568903

134. Zhang Y-F, Xu H-M, Yu F, Wang M, Li M-Y, Xu T, et al. Crosstalk between MicroRNAs and Peroxisome Proliferator-Activated Receptors and Their Emerging Regulatory Roles in Cardiovascular Pathophysiology. PPAR Res [Internet]. 2018 Dec 5 [cited 2019 Mar 29];2018:1-11. Available from: http://www.ncbi.nlm.nih.gov/pubmed/30622558

135. Zeviani M, Masanori N, Herbert J, Lomax MI, Grossman LI, Sherbany AA, et al. Isolation of a cDNA clone encoding subunit IV of human cytochrome c oxidase. Gene. 1987 Jan 1;55(2-3):205-17.

136. Loeffen JLCM, Triepels RH, Van Den Heuvel LP, Schuelke M, Buskens CAF, Smeets RJP, et al. cDNA of eight nuclear encoded subunits of NADH:ubiquinone oxidoreductase: Human complex I cDNA characterization completed. Biochem Biophys Res Commun [Internet]. 1998 Dec 18 [cited 2020 Mar 26];253(2):415-22. Available from:

https://linkinghub.elsevier.com/retrieve/pii/S0006291X98997868

137. Loublier S, Bayot A, Rak M, El-Khoury R, Bénit $P$, Rustin $P$. The NDUFB6 subunit of the mitochondrial respiratory chain complex I is required for electron transfer activity: A proof of principle study on stable and controlled RNA interference in human cell lines. Biochem Biophys Res Commun. 2011 Oct 22;414(2):367-72.

138. Hirawake H, Taniwaki M, Tamura A, Kojima S, Kita K. Cytochrome win human complex II (succinate-ubiquinoneoxidoreductase): cDNA cloning of the components in liver mitochondria and chromosome assignment of the genes for the large (SDHC) and small (SDHD) subunitsto 1q21 and 11q23. Cytogenet Genome Res [Internet]. 1997 Jan 1 [cited 2020 Mar 26];79(1-2):132-8. Available from: https://www.karger.com/Article/FullText/134700

139. Chen WW, Birsoy K, Mihaylova MM, Snitkin H, Stasinski I, Yucel B, et al. Inhibition of ATPIF1 ameliorates severe mitochondrial respiratory chain dysfunction in mammalian cells. Cell Rep. 2014 Oct 4;7(1):27-34.

140. Lefebvre V, Du Q, Baird S, Ng ACH, Nascimento M, Campanella M, et al. Genome-wide RNAi screen identifies ATPase inhibitory factor 1 (ATPIF1) as essential for PARK2 recruitment and 
mitophagy. Autophagy. 2013;9(11):1770-9.

141. Wei TC, Lin HY, Lu CC, Chen CM, You LR. Expression of Crip2, a LIM-domain-only protein, in the mouse cardiovascular system under physiological and pathological conditions. Gene Expr Patterns. 2011 Oct;11(7):384-94.

142. Sun X, Zhang $R$, Lin X, Xu X. Wnt3a regulates the development of cardiac neural crest cells by modulating expression of cysteine-rich intestinal protein 2 in rhombomere 6. Circ Res [Internet]. 2008 Apr 11 [cited 2020 Jan 28];102(7):831-9. Available from:

http://www.ncbi.nlm.nih.gov/pubmed/18292601

143. Trembinski DJ, Bink DI, Theodorou K, Sommer J, Fischer A, van Bergen A, et al. Aging-regulated anti-apoptotic long non-coding RNA Sarrah augments recovery from acute myocardial infarction. Nat Commun [Internet]. 2020 Dec 1 [cited 2020 Aug 12];11(1):1-14. Available from: https://doi.org/10.1038/s41467-020-15995-2

144. Zhuchenko O, Wehnert M, Bailey J, Zhong SS, Cheng CL. Isolation, mapping, and genomic structure of an X-linked gene for a subunit of human mitochondrial complex I. Genomics. 1996 Nov 1;37(3):281-8.

145. Ohta S, Goto K, Arai H, Kagawa Y. An extremely acidic amino-terminal presequence of the precursor for the human mitochondrial hinge protein. FEBS Lett. 1987 Dec 21;226(1):171-5.

146. Callegari S, Richter F, Chojnacka K, Jans DC, Lorenzi I, Pacheu-Grau D, et al. TIM29 is a subunit of the human carrier translocase required for protein transport. Vol. 590, FEBS Letters. Wiley Blackwell; 2016. p. 4147-58. 